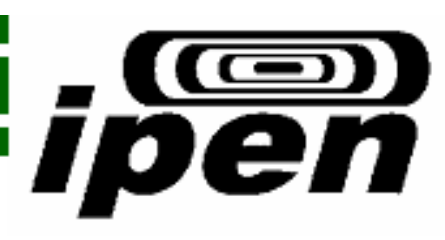

Autarquia associada à Universidade de São Paulo

\title{
AVALIAÇÃO DOSIMÉTRICA DA RESPOSTA ESPECTROFOTOMÉTRICA DA SOLUÇÃO GEL DE ALANINA PARA RADIAÇÃO GAMA, DE FÓTONS, DE ELÉTRONS E DE NÊUTRONS TÉRMICOS
}

\section{Cléber Feijó Silva}

Dissertação apresentada como parte dos requisitos para obtenção do Grau de Mestre em Ciências na Área de Tecnologia Nuclear - Aplicações.

Orientadora:

Dra. Letícia L. C. Rodrigues

\section{SÃO PAULO}




\title{
INSTITUTO DE PESQUISAS ENERGÉTICAS E NUCLEARES
}

Autarquia associada à Universidade de São Paulo

\section{AVALIAÇÃO DOSIMÉTRICA DA RESPOSTA ESPECTROFOTOMÉTRICA DA SOLUÇÃO GEL DE ALANINA PARA RADIAÇÃO GAMA, DE FÓTONS, DE ELÉTRONS E DE NÊUTRONS TÉRMICOS}

\section{Cléber Feijó Silva}

\begin{abstract}
Dissertação apresentada como parte dos requisitos para obtenção do Grau de Mestre em Ciências na Área de Tecnologia Nuclear - Aplicações.
\end{abstract}

Orientadora:

Dra. Letícia L.C. Rodrigues

SÃO PAULO

2009 
Aos meus pais, Marina e Braz, e também à minha irmã Letícia. 
"Toda a nossa ciência, comparada com a realidade é primitiva e infantil - e, no entanto é a coisa mais preciosa que temos".

Albert Einstein (1879 - 1955). 


\section{AGRADECIMENTOS}

À minha orientadora, Dra. Letícia L. C. Rodrigues, pela minha iniciação na área da tecnologia nuclear, paciência, confiança, credibilidade, amizade e por todas as oportunidades de crescimento que me proporcionou durante a orientação do mestrado.

Ao IPEN, na pessoa do Sr. Superintendente, Dr. Nilson Dias Vieira Jr, pela oportunidade de executar este trabalho.

À Comissão Nacional de Energia Nuclear (CNEN), Fundação de Amparo do Estado de São Paulo (FAPESP), Conselho Nacional do Desenvolvimento Científico e Tecnológico (CNPq) e a Coordenação de Aperfeiçoamento de Pessoal de Nível Superior (CAPES) pelo auxílio financeiro que permitiu a dedicação exclusiva ao trabalho de pesquisa.

À Dra. Linda V. E. Caldas, sempre muito prestativa, e a todos os alunos e funcionários do GMR, que me deram total apoio durante este trabalho.

Ao Dr. Paulo Rogério Pinto Coelho, pelo auxílio e atenção durante as irradiações no BH\#3 do Reator de Pesquisa do IPEN.

À Dra Laura Natal Rodrigues e ao físico Marcelo Ribeiro Piciolli, pelas irradiações das amostras no acelerador da Divisão de Oncologia do Instituto de Radiologia (InRad) do Hospital das Clínicas (HC) da Faculdade de Medicina da Universidade de São Paulo (FM-USP), pelo auxílio e amizade.

À Srª Donata Celicea de O. Zanin, pelo apoio, auxílio e amizade.

Ao Eng. Carlos G. da Silveira e à Eng ${ }^{\underline{a}}$ Elizabeth S.R. Somessari, do Centro de Tecnologia das Radiações (CTR), pelo auxílio durante as irradiações, pelos esclarecimentos e amizade. 
Aos pós-graduandos, Thyago Fressatti Mangueira, pelos trabalhos conjuntos durante todo o mestrado e amizade, Rodrigo Ferreira de Lucena, pela amizade desde o tempo do curso pré-vestibular, e Maíra Goes Nunes, pela amizade.

Aos funcionários e professores da Escola Estadual "Cassiano Ricardo", em especial, aos professores Adaulto Campos, Arlete Sotelo, Dora Zimpeck, e Pedro, por acreditar no meu potencial.

Aos amigos, Alexandre Soares de Sousa, pelo grande incentivo e amizade, e Ricardo Bender, pela amizade.

Aos meus pais, Marina e Braz, à minha irmã Letícia, pelo apoio incondicional, afeto e carinho.

A todos os amigos que direta ou indiretamente contribuíram para a realização deste trabalho. 


\title{
AVALIAÇÃO DOSIMÉTRICA DA RESPOSTA ESPECTROFOTOMÉTRICA DA SOLUÇÃO GEL DE ALANINA PARA RADIAÇÃO GAMA, DE FÓTONS, DE ELÉTRONS E DE NÊUTRONS TÉRMICOS
}

\author{
Cléber Feijó Silva
}

\section{RESUMO}

O dosímetro alanina gel é um novo material na forma de gel desenvolvido pelo IPEN, que apresenta uma melhora significativa em relação ao sistema a base de Alanina desenvolvido por Costa. A DL-Alanina $\left(\mathrm{C}_{3} \mathrm{H}_{7} \mathrm{NO}_{2}\right)$ é um aminoácido tecido equivalente que favorece a produção de íons Férricos na solução. Este trabalho visa analisar as principais características dosimétricas deste novo material na forma de gel para futura aplicação na medida da distribuição da dose. Foi avaliado o desempenho da solução gel de Alanina para radiação gama, de fótons, de elétrons e de nêutrons térmicos utilizando a técnica de espectrofotometria. De acordo com os resultados obtidos para os diferentes tipos de radiação estudados, as reprodutibilidades intra e inter-lotes são melhores que $4 \%$ e $5 \%$, respectivamente. A resposta em função da dose apresenta um comportamento linear para o intervalo de dose estudado. A dependência da resposta em função da taxa de dose e energia da radiação incidente é melhor que $2 \%$ e $3 \%$, respectivamente. A dose mínima detectável é 0,1 Gy. Os resultados obtidos indicam que o dosímetro Alanina gel apresenta um bom desempenho, e pode ser usado como dosímetro alternativo na área de radioterapia, utilizando a técnica de ressonância magnética para avaliar a distribuição tridimensional de dose. 


\title{
DOSIMETRIC EVALUATION OF SPECTROPHOTOMETRIC RESPONSE OF ALANINE GEL SOLUTION FOR GAMMA, PHOTONS, ELECTRONS AND THERMAL NEUTRONS RADIATIONS
}

\author{
Cléber Feijó Silva
}

\begin{abstract}
Alanine Gel Dosimeter is a new gel material developed at IPEN that presents significant improvement on Alanine system developed by Costa. The DL-Alanine $\left(\mathrm{C}_{3} \mathrm{H}_{7} \mathrm{NO}_{2}\right)$ is an amino acid tissue equivalent that improves the production of ferric ions in the solution. This work aims to analyse the main dosimetric characteristics this new gel material for future application to measure dose distribution. The performance of Alanine gel solution was evaluated to gamma, photons, electrons and thermal neutrons radiations using the spectrophometry technique. According to the obtained results for the different studied radiation types, the reproducibility intra-batches and inter-batches is better than $4 \%$ and $5 \%$, respectively. The dose response presents a linear behavior in the studied dose range. The response dependence as a function of dose rate and incident energy is better $2 \%$ and $3 \%$, respectively. The lower detectable dose is $0.1 \mathrm{~Gy}$. The obtained results indicate that the Alanine gel dosimeter presents good performance and can be useful as an alternative dosimeter in the radiotherapy area, using MRI technique for tridimensional dose distribution evaluation.
\end{abstract}




\section{SUMÁRIO}

Página

Lista de Figuras .......................................................................... xiii

Lista de Tabelas......................................................................... xvi

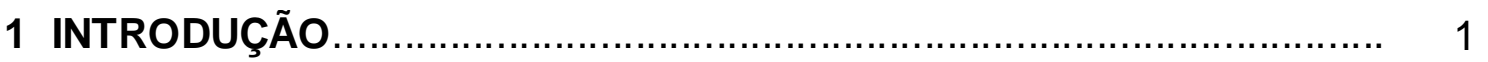

2 OBJETIVOS

3 FUNDAMENTOS TEÓRICOS ................................................................ 5

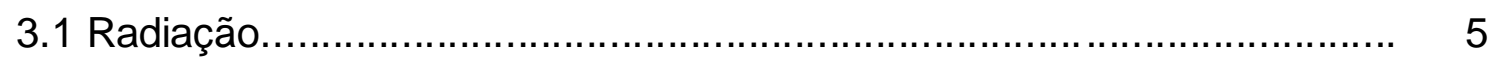

3.2 Interações de Partículas com a matéria................................................ 6

3.2.1 Poder de Freamento (Stopping Power)........................................... 6

3.2.2 Poder de Espalhamento (Scattering Power)..................................... 7

3.2.3 Interações do feixe de Elétrons com a matéria.................................... 7

3.3 Interações do feixe de Fótons com a matéria ….................................... 7

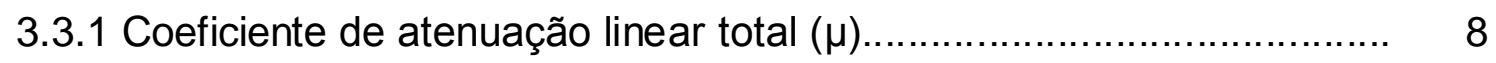

3.4 Interação de Nêutrons com a matéria..................................................... 9

3.4.1 Espalhamento .................................................................... 9

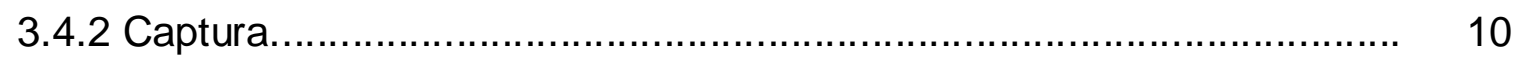

3.5 Dosimetria das radiações.............................................................. 10

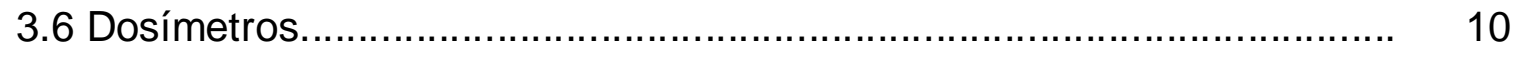

3.7 Dose Absorvida....................................................................... 11

3.8 Propriedades Dosimétricas........................................................... 12

3.8.1 Linearidade ......................................................................... 13

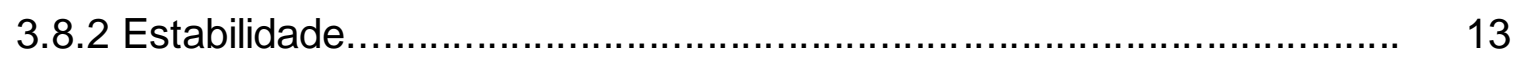

3.8.3 Reprodutibilidade................................................................. 13

3.9 Influência de Fatores Externos na Dosimetria das Radiações................. 14

3.9.1 Dependência Energética................................................................ 14

3.9.2 Taxa de Dose..................................................................... 14

3.9.3 Condições Ambientais.............................................................. 15

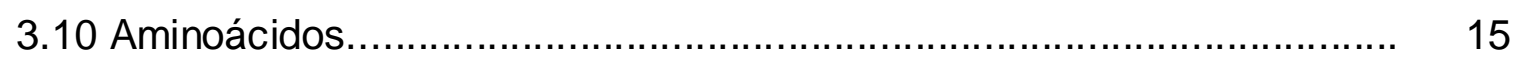




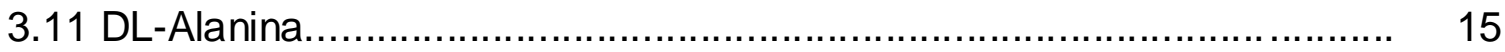

3.11.1 Interação da radiação com a DL-Alanina........................................ 16

3.12 Dosimetria Química...................................................................... 16

3.13 Aplicações da Dosimetria Química em forma de gel........................... 19

3.13.1 Radioterapia......................................................................... 20

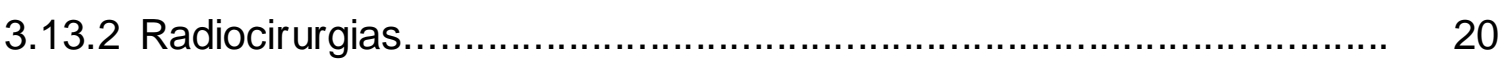

3.13.3 Gamma Knife................................................................... 20

3.13.4 Terapia de Captura de Nêutrons com Boro.................................... 21

3.13.5 Acelerador Linear................................................................... 22

3.13.6 Terapia de Radiação com Intensidade Modulada (TRIM)................. 23

3.13.7 Dosimetria 2D pela Técnica de Absorção Óptica (AO)...................... 23

3.13.8 Dosimetria 3D pela Técnica de Imageamento por Ressonância Magnética (IRM) ........................................................................... 24

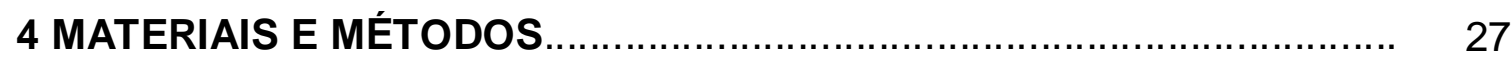

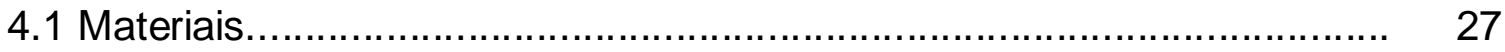

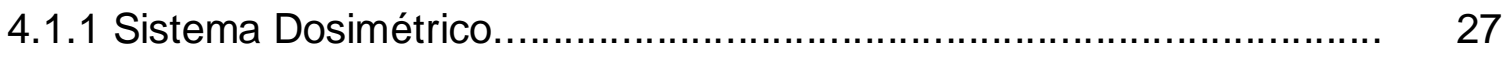

4.1.2 Balança de Precisão............................................................... 27

4.1.3 Preparação do gel.................................................................. 28

4.1.4 Objeto Simulador.................................................................. 29

4.2 Sistemas de Irradiação................................................................. 29

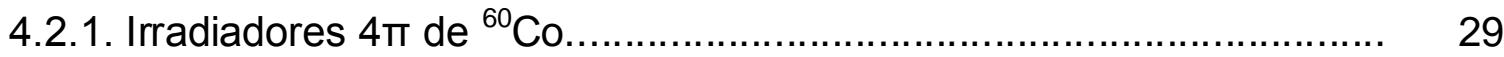

4.2.1.1 Fonte Panorâmica.......................................................................... 30

4.2.1.2 Fonte Gammacell........................................................... 31

4.2.1.3 Arranjo Experimental para irradiação nos irradiadores 4 m.............. 32

4.2.2 Acelerador de Elétrons Dynamitron Job 188 (Aplicações Industriais).. $\quad 32$

4.2.3 Acelerador Linear Clinac 2100-C Varian (Aplicações Clínicas)............ 34

4.2.4 Reator de Pesquisa................................................................... 35

4.3 Leitura do sinal óptico.................................................................. 36

4.4 Comportamento da solução gel de Alanina para diferentes tipos de radiações................................................................................. 37

4.4.1 Tratamento dos Dados............................................................... 37 


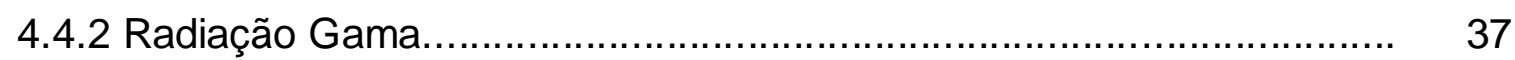

4.4.2.1 Determinação do tempo de estocagem do gel pré-irradiação........... 37

4.4.2.2 Dose resposta/Reprodutibilidade................................................... 38

4.4.2.3 Dependência da resposta com a taxa de dose............................... 38

4.4.2.4 Estabilidade............................................................................ 38

4.4.3 Feixe Clínico de Fótons................................................................. 38

4.4.3.1 Dose Resposta/Reprodutibilidade................................................ 39

4.4.3.2 Dependência Energética.......................................................... 39

4.4.3.3 Dependência da resposta com a taxa de dose............................... 39

4.4.4 Feixe Clínico de Elétrons................................................................... 39

4.4.4.1 Dose Resposta/Reprodutibilidade............................................ 39

4.4.4.2 Dependência Energética......................................................... 40

4.4.4.3 Dependência da resposta com a taxa de dose.............................. 40

4.4.4.4 Estabilidade....................................................................... 40

4.4.5 Elétrons Aplicações Industriais...................................................... 40

4.4.5.1 Dose Resposta/Reprodutibilidade............................................ 41

4.4.6 Nêutrons Térmicos do Reator de Pesquisa....................................... 41

4.4.6.1 Dose Resposta/Reprodutibilidade.............................................. 41

4.4.6.2 Avaliação da dose gama/nêutrons no Reator de Pesquisa.............. 41

4.4.7 Limite mínimo de Detecção............................................................. 42

5 RESULT ADOS E DISCUSSÕES...................................................... 43

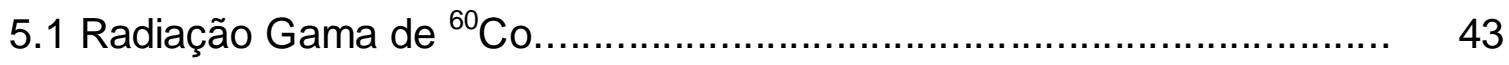

5.1.1 Espectro típico da solução gel de Alanina para radiação de ${ }^{60} \mathrm{Co}$........ 43

5.1.2 Determinação do tempo ótimo de estocagem do gel para irradiação... 43

5.1.3 Dose Resposta.......................................................................... 44

5.1.4 Reprodutibilidade.................................................................. 45

5.1.5 Dependência da resposta com a Taxa de dose................................ 46

5.1.6 Estabilidade........................................................................... 47

5.2 Feixe Clínico de Fótons................................................................ 48

5.2.1 Espectro típico da solução gel de Alanina para radiação de Feixe Clínico de Fótons. 


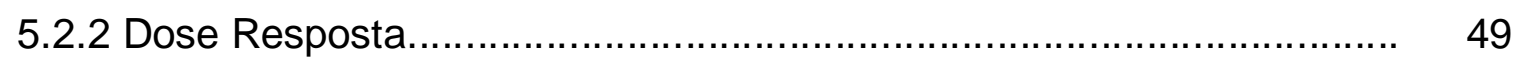

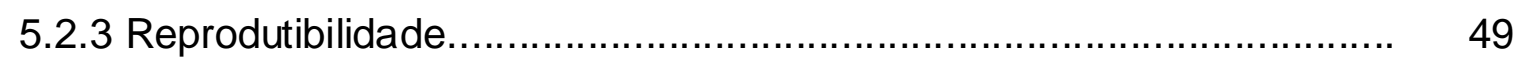

5.2.4 Dependência Energética da Resposta............................................ 50

5.2.5 Dependência da Resposta com a Taxa de dose................................ 51

5.2.6 Estabilidade............................................................................ 52

5.3 Feixe Clínico de Elétrons............................................................... 52

5.3.1 Espectro típico da solução de Alanina para Feixe Clínico de

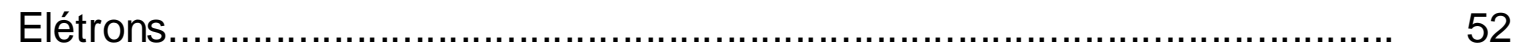

5.3.2 Dose Resposta........................................................................ 53

5.3.3 Reprodutibilidade....................................................................... 53

5.3.4 Dependência Energética.......................................................... 54

5.3.5 Dependência da Resposta com a Taxa de dose.............................. 55

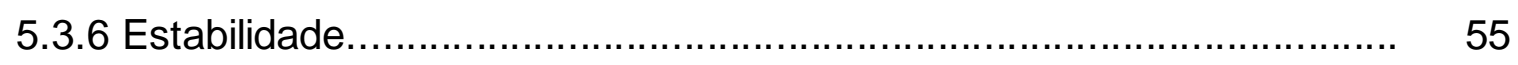

5.4 Comparação da curva de dose resposta da solução gel de Alanina para radiação de ${ }^{60} \mathrm{Co}$ e Feixes Clínicos de Fótons e Elétrons....................

5.5 Elétrons (Aplicações Industriais) ........................................................ 57

5.5.1 Espectro típico da solução gel de Alanina para Elétrons (Aplicações

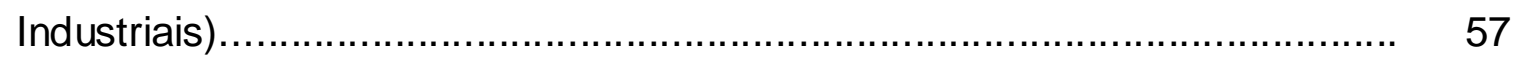

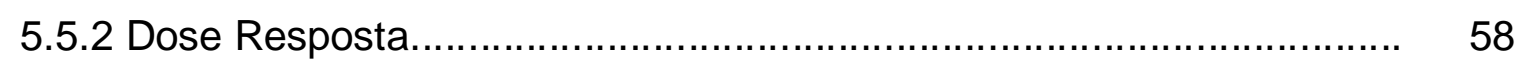

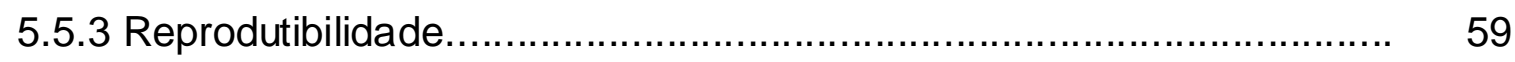

5.6 Nêutrons Térmicos................................................................... 59

5.6.1 Espectro típico da solução gel de Alanina para nêutrons.................... 59

5.6.2 Dose Resposta...................................................................... 60

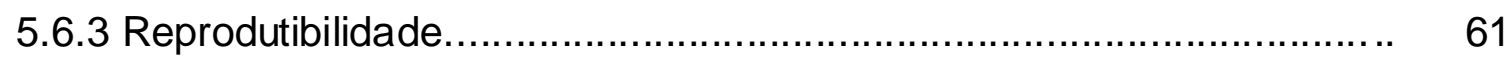

5.6.4 Avaliação da dose gama/nêutrons no Reator.................................... 62

5.7 Limite Mínimo de Detecção.................................................................. 64

5.8 Incertezas nas medidas................................................................ 64

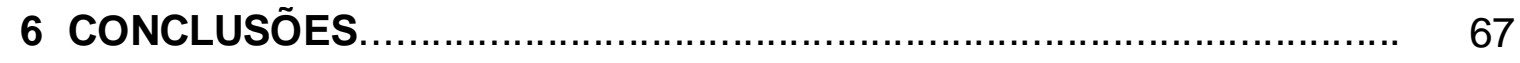

REFERÊNCIAS BIBLIOGRÁFICAS................................................. 68 


\section{Lista de Figuras}

Página

FIGURA 1: Espectro Eletromagnético.

FIGURA 2: Espectro de Absorção da solução gel de Alanina para radiação de ${ }^{60} \mathrm{Co}$.

FIGURA 3: Variação da tonalidade de cor na solução gel de Alanina em função da dose.

FIGURA 4: Esquema do instrumento Gamma-Knife.

FIGURA 5: Dimensôes externas da cubeta de acrílico para a leitura no espectrofotômetro.

FIGURA 6: Suporte de acrílico com as cubetas no centro para a irradiação.

FIGURA 7: Fonte Panorâmica pertencente ao Centro de Tecnologia das

Radiações/IPEN.

FIGURA 8: Irradiador tipo Gammacell pertencente ao Centro de

Tecnologia das radiações/IPEN.

FIGURA 9: Acelerador de Elétrons Dynamiltron Job 188 pertencente ao

Centro de Tecnologia das Radiações/IPEN.

FIGURA 10: Sistema de irradiação no Acelerador Clinac 2100-C do

Hospital das Clínicas/USP

FIGURA 11: Esquema em corte horizontal do $\mathrm{BH} 3$ do reator de pesquisa IEA-R1 com o suporte na "posição da amostra".

FIGURA 12: Espectro típico da solução gel de Alanina para radiação gama de ${ }^{60} \mathrm{Co}$.

FIGURA 13: Resposta óptica da solução gel de Alanina para o período de estocagem pré-irradiação.

FIGURA 14: Resposta óptica da solução gel de Alanina entre 20 e 54 h de estocagem pré-irradiação.

FIGURA 15: Curva de dose-resposta da solução gel de Alanina para radiação gama. 
FIGURA 16: Reprodutibilidade inter-lotes da solução gel de Alanina para

radiação gama.

FIGURA 17: Dependência da resposta da solução gel de Alanina em

função da taxa de dose.

FIGURA 18: Resposta da solução gel de Alanina como uma função do tempo de estocagem após a irradiação.

FIGURA 19: Resposta da solução gel de Alanina como uma função do tempo de estocagem após a irradiação.

FIGURA 20: Espectro típico da solução gel de Alanina para radiação de feixe clínico de fótons.

FIGURA 21: Curva de dose resposta da solução gel de Alanina para fótons de $6 \mathrm{MeV}$.

FIGURA 22: Reprodutibilidade inter-lotes da resposta da solução gel de Alanina para radiação de fótons de $6 \mathrm{MeV}$.

FIGURA 23: Dependência Energética relativa à radiação gama do ${ }^{60} \mathrm{Co}$ da resposta da solução gel de Alanina para feixe clínico de fótons.

FIGURA 24: Dependência da resposta da solução gel de Alanina em função da taxa de dose para dose de 5 Gy

FIGURA 25: Espectro típico da solução gel de Alanina para radiação de feixe clínico de elétrons.

FIGURA 26: Curva de dose resposta da solução gel de Alanina para feixe clínico de elétrons

FIGURA 27: Reprodutibilidade inter-lotes da resposta da solução gel de Alanina para feixe clínico de elétrons

FIGURA 28: Dependência energética relativa da resposta da solução gel de Alanina para feixe clínico de elétrons.

FIGURA 29: Dependência da resposta da solução gel de Alanina em função da taxa de dose para feixe clínico de elétrons

FIGURA 30: Resposta da solução gel de Alanina em função do tempo de estocagem após a irradiação. 
FIGURA 31: Resposta da solução gel de Alanina em função do tempo de estocagem após a irradiação.

FIGURA 32: Espectro típico da solução gel de Alanina para elétrons (aplicações industriais).

FIGURA 33: Curva de resposta da solução gel de Alanina em função da dose.

FIGURA 34: Espectro típico da solução gel de Alanina para campos mistos gama/nêutrons. 60

FIGURA 35: Curva de dose resposta da solução gel de Alanina com ${ }^{10} \mathrm{~B}$ para campos mistos gama/nêutron

FIGURA 36: Reprodutibilidade inter-lotes para a solução gel de Alanina

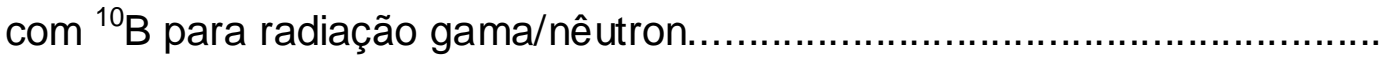

FIGURA 37: Curva de dose-resposta para a solução gel de Alanina com e sem a adição ${ }^{10} \mathrm{~B}$ para radiação gama do ${ }^{60} \mathrm{Co}$ 63 FIGURA 38: Curva de dose resposta para nêutrons térmicos do reator para a solução gel de Alanina com ${ }^{10} \mathrm{~B}$. 


\section{Lista de Tabelas}

Página

TABELA 1: Classificação dos nêutrons segundo a sua energia................... 9

TABELA 2: Dados envolvidos nas reações de ${ }^{10} \mathrm{~B}$ com nêutrons................. 22

TABELA 3: Composição química da solução gel de Alanina........................ 27

TABELA 4: Parâmetros da fonte Panorâmica............................................ 31

TABELA 5: Parâmetros da fonte Gammacell........................................... 31

TABELA 6: Parâmetros de irradiação do Acelerador de Elétrons

Dynamiltron Job 188 pertencente ao Centro de Tecnologia das

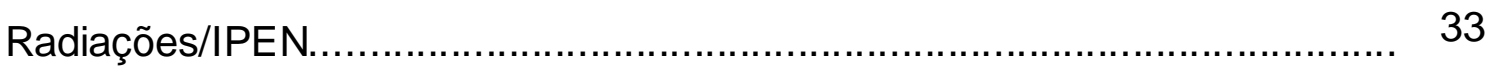

TABELA 7: Parâmetros de irradiação do acelerador linear clinac 2100-C da Varian.

TABELA 8: Parâmetros de medida do Espectrofôtometro Shimadzu

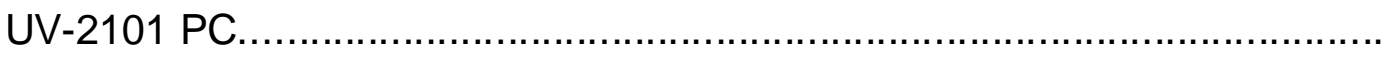

TABELA 9: Sensibilidade da solução gel de Alanina em função de

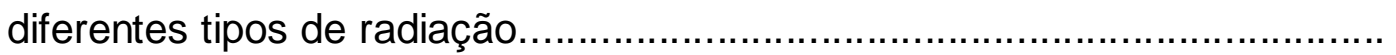

TABELA 10: Limite mínimo de detecção da solução gel de Alanina para diversos tipos de radiação. 


\section{INTRODUÇÃO}

A radiação ionizante oferece vantagens tecnológicas nunca antes obtidas. Atualmente, a esterilização de produtos médicos, a preservação de alimentos pela esterilização e a radioterapia são algumas destas vantagens. Os recentes avanços na tecnologia de tratamentos com radiação, tais como Gamma Knife e radiocirurgias, forneceram meios alternativos para os médicos tratarem pacientes com tumor de cérebro e outros tipos de tumores que não podem ser efetivamente tratados pelos procedimentos convencionais de terapia com radiação.

Com os avanços dos tratamentos na área de medicina, a aplicação da radiação ionizante tornou-se um instrumento imprescindível para o desenvolvimento desta área, já que o seu emprego no tratamento de doenças é menos invasivo e possibilita o tratamento de certas doenças que os métodos convencionais não podem ser aplicados, sejam pela dificuldade ou por danificarem as estruturas vitais dos seres humanos, consequentemente, possibilita um tratamento mais efetivo e adequado de certas doenças. Em Radioterapia, os aceleradores clínicos (LINAC) são amplamente usados, pois podem produzir feixes de fótons e elétrons com várias energias, podendo ser utilizado no tratamento de várias doenças. Em geral, os tratamentos de tumores mais profundos são utilizados feixes de fótons, e para tumores mais superficiais com baixo poder de disseminação são utilizados os feixes de elétrons (Podgorsak, 2005). Para tratamentos de tumores complexos podem ser usadas as técnicas Gamma Knife, que consiste em uma dose alta de radiação gama em um ponto-alvo da cabeça em uma única aplicação, poupando as regiões ao redor (Dong et al, 1996), Terapia de Captura de Nêutrons (BNCT), que consiste da interação de nêutrons lentos com o radioisótopo ${ }^{10} \mathrm{~B}$ injetado no tumor, que permite uma relação dose tumor/tecido sadio maior, poupando os tecidos em volta do tumor (Gambarini et al, 2002), ou a Terapia de Radiação com Intensidade Modulada (TRIM), que permite uma distribuição de dose conformal mais precisa em torno de 
uma área alvo, ou seja, permite moldar de forma aproximada o tumor em questão, já que é possível controlar a intensidade do feixe de radiação.

O sucesso da terapia com radiações ionizantes depende de quão próximo está o valor da dose administrada ao paciente daquela prescrita, ou seja, uma maior exatidão e acurácia possíveis para determinação da dose absorvida (Hubell,1982). Desse modo, uma maneira de se comparar essas duas doses absorvidas é através da dosimetria.

Com o crescimento do emprego da radiação ionizante na área médica e o aumento das doses aplicadas nos procedimentos médicos, a demanda por um mapeamento tridimensional da distribuição das doses é imprescindível.

Os métodos convencionais disponíveis para avaliação da dose absorvida não apresentam um caráter tridimensional, pois em grande parte empregam materiais dosimétricos que não possuem boa equivalência com o tecido (Horowitz, 1994) ou é necessário o uso extensivo de cálculos computacionais (Moraes, 2006) e calibrações, tornando inviáveis na pratica cotidiana hospitalar.

Gore (1984) combinou a solução aquosa Fricke padrão em uma matriz em forma de gel, com a técnica de imagem por ressonância magnética (IRM), com isso tornou possível a dosimetria química gel tri-dimensional. O surgimento da dosimetria química utilizando uma matriz em forma de gel apresenta um potencial de definição da dose de radiação absorvida de uma forma mais precisa, pois podem ser realizados diferentes cortes de um volume com o propósito de se estudar a distribuição de doses de radiação em diferentes planos. Entretanto, o maior problema relacionado a este sistema é a difusão dos íons férricos que, consequentemente, acarreta perda de informação espacial ao longo do tempo. Em 1992, um novo dosímetro em forma de gel foi desenvolvido, este novo sistema combinou a polimerização e o "cross linking" dos monômeros acrilamida e N,N'- acrilamida-bismetileno (bis) com uma matriz de agarose aquosa, eliminando o problema da difusão, entretanto, requer uma atmosfera controlada, ausência de oxigênio, e não é facilmente manipulado e descartado, já que é um produto tóxico (Maryanski, 1993; Baldock, 1998). 
Com todas estas aplicações, é necessário um sistema dosimétrico que garanta que o tratamento a ser aplicado esta sendo realizado corretamente, por isso a dosimetria gel tem se mostrado bastante eficiente, pois aliada às técnicas de IRM e Tomografia Computadorizada (CT) é possível fazer a verificação da dose tridimensionalmente.

Devido ao grande potencial de materiais em forma de gel, desenvolver um novo sistema dosimétrico que possa ser alternativo aos existentes tornou-se imprescindível para o desenvolvimento desta área. Este trabalho avalia a viabilidade de aplicação de um novo sistema dosimétrico baseado no emprego da Alanina em forma de gel, já que a Alanina é um material equivalente ao tecido para efeitos da interação da radiação ionizante com a matéria, custo baixo e de fácil aquisição no mercado nacional, como um dosímetro para aplicação na área médica (clínica), empregando as técnicas de Absorção Óptica (AO), que fornece uma distribuição bidimensional, e, futuramente, Imageamento por Ressonância Magnética (IRM), para a obtenção de uma distribuição tridimensional. 


\section{OBJETIVOS}

\section{Gerais}

Avaliação dosimétrica da resposta espectrofotométrica da solução Alanina gel para Radiação Gama, de Fótons, de Elétrons e de Nêutrons.

\section{Específicos}

- Padronizar a metodologia para obtenção de solução de Alanina na forma de gel;

- Estudar as propriedades dosimétricas da solução gel de Alanina exposto à radiação gama, de fótons de energia alta, de elétrons e de nêutrons térmicos, empregando a técnica de espectrofotometria $(\mathrm{AO})$;

- Propor um Gel Dosimétrico baseado em DL-Alanina e Ferro II para ser empregado na medida da distribuição tridimensional da dose de radiação usando a técnica de IRM. 


\section{FUNDAMENTOS TEÓRICOS}

\subsection{Radiação}

São ondas eletromagnéticas ou partículas (com ou sem carga elétrica) que se propagam com alta velocidade e, portando, energia, e que, ao interagir podem produzir variados efeitos sobre a matéria.

As radiações eletromagnéticas mais conhecidas são mostradas na FIG.1:

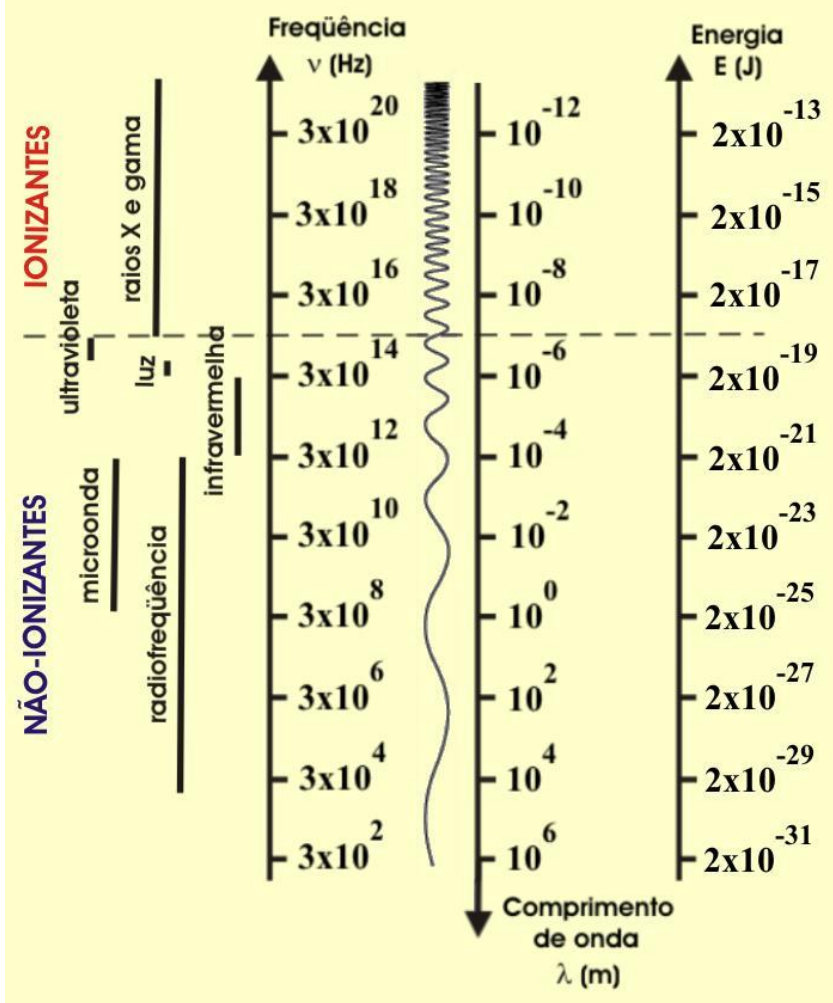

FIGURA 1: Espectro Eletromagnético (Tosi, 2005).

As radiações sob a forma de partículas, com massa e carga elétrica, mais comuns são: feixes de elétrons, feixes de prótons, radiação beta e radiação alfa. Das 
radiações particuladas sem carga elétrica, a mais conhecida é o nêutron (Tauhata et al, 2003).

A radiação pode ser dividida em radiação ionizante, que produz ionização nos materiais, e não-ionizante. Sendo que a radiação ionizante pode ser subdividida em diretamente, partículas detentoras de carga elétrica, e indiretamente ionizante, ondas eletromagnéticas e partículas sem carga elétrica.

\subsection{Interações de Partículas com a matéria (Tauhata et al, 2003)}

As partículas ao interagirem com a matéria produzem efeitos como a excitação atômica ou molecular, ionização, ativação do núcleo ou radiação de freamento.

$\mathrm{Na}$ excitação atômica ou molecular, os elétrons do átomo ou molécula são deslocados de seus orbitais em equilíbrio para orbitais mais energéticos, e quando retornam emitem a energia excedente em forma de luz ou raios $\mathrm{X}$ característicos.

$\mathrm{Na}$ ionização, os elétrons são removidos dos orbitais do átomo ou molécula, resultando em íons positivos ou radicais livres, no caso de haver uma quebra de uma ligação química.

$\mathrm{Na}$ ativação do núcleo, as partículas com energia superior à energia de ligação dos nucleons podem provocar reações nucleares, culminando em um núcleo residual excitado ou não e a emissão de radiação.

$\mathrm{Na}$ radiação de freamento, o campo elétrico das partículas carregadas interage com o campo elétrico do átomo, sendo que parte da energia cinética da partícula é convertida em radiação eletromagnética, aproximadamente 5\%.

\subsubsection{Poder de Freamento (Stopping Power)}

Poder de freamento (S) é a energia inelástica perdida $(d E)$ por uma partícula carregada em um determinado comprimento $(d x)$. O poder de freamento total $\left(S_{\text {total }}\right)$ é dividido em duas componentes, Poder de freamento colisional e radioativo (Podgorsak, 2005), veja EQ.1: 


$$
S_{\text {total }}=\frac{d E}{d x}{ }_{\text {Colisional }}+\frac{d E}{d x}_{\text {Radiativo }}
$$

O poder de freamento colisional tem um papel importante na dosimetria das radiações, já que a dose em um meio é expressa pelo produto da fluência de elétrons pelo poder de freamento colisional.

\subsubsection{Poder de Espalhamento (Scattering Power)}

Poder de espalhamento (T) é a média quadrática do ângulo de espalhamento $(\theta)$ pelo comprimento (I), como é mostrado na EQ.2:

$$
T=\frac{\overline{d \theta^{2}}}{d l}
$$

\subsubsection{Interações do feixe de Elétrons com a matéria}

As interações dos elétrons com a matéria podem ser através de interações Coulombianas com os elétrons do orbital atômico e o próprio núcleo atômico. $O$ elétron perde sua energia através de colisões ou perda radiativa (energia cinética), ou por espalhamento (mudança da trajetória dos elétrons). As grandezas que descrevem as perdas por energia cinética e de espalhamento são o poder de freamento e o poder espalhamento, respectivamente (Podgorsak, 2005).

As colisões entre o elétron incidente com elétrons do orbital atômico ou com o núcleo podem ser divididas em elásticas e inelásticas. Sendo que nas colisões elásticas não há perda de energia do elétron incidente, há apenas uma mudança na trajetória, enquanto que nas colisões inelásticas, também há a mudança de trajetória do elétron incidente, mas com transferência de energia para elétron orbital, ou ocorre a emissão em forma de radiação devido ao freamento da partícula (Bremsstrahlung) (Attix, 1986).

\subsection{Interações dos feixes de Fótons com a matéria}

A interação entre fótons e a matéria depende da energia do feixe e do número atômico do material. Devido à ausência de massa de repouso e carga 
elétrica, tem um alto poder de penetrabilidade. A penetrabilidade dos Raios $\mathrm{X}$ e gama é muito maior que as partículas carregadas. Os principais processos de interação da radiação com a matéria são (Podgorsak, 2005):

Efeito fotoelétrico: é caracterizado pela transferência total de energia da radiação $\mathrm{X}$ ou gama (completamente absorvido) pelo elétron orbital, que é expelido com uma energia cinética bem definida;

Efeito Compton Coerente: é caracterizado pelo espalhamento de um fóton com um elétron com alta energia de ligação. Não há perda de energia do fóton, sendo que o fóton muda de direção;

Efeito Compton Incoerente: é caracterizado pelo espalhamento de um fóton com um elétron com baixa energia de ligação. Parte da energia do fóton é absorvida por este elétron, sendo que o fóton muda de direção;

Produção de Pares: é a interação de fótons com energia superior a 1,022 MeV com o campo elétrico do núcleo atômico. Nesta interação há a criação de um par de partículas elétrons-pósitrons.

\subsubsection{Coeficiente de atenuação linear total $(\mu)$}

Quando um fóton com energia hvincide sobre um material com certa espessura $x$, uma parte da energia será espalhada e/ou absorvida (processos descritos no item 3.3), enquanto que a outra parte da energia atravessará o material sem interagir. A grandeza que expressa a probabilidade da intensidade do feixe de fótons ser atenuado é o coeficiente de atenuação linear total. O coeficiente de atenuação linear total é a soma das probabilidades dos efeitos que ocorrem quando o feixe atravessa o material, negligenciando as reações fótons nucleares e o espalhamento Rayleigh, como é descrito pela EQ.3 (Tauhata et al, 2003):

$$
\mu=\tau+\sigma+\kappa
$$

Onde:

$\tau$ : probabilidade do fóton ser espalhado ou absorvido por efeito Compton;

$\sigma:$ probabilidade de ocorrer o efeito fotoelétrico;

$\kappa$ : probabilidade de ocorrer o efeito produção dos pares. 
O coeficiente de atenuação linear total, para um mesmo material e fótons de mesma energia, depende do estado físico e forma alotrópica do material. Por isso, definiu-se o coeficiente mássico de atenuação $(\mu / \rho)$, ou seja, a razão entre coeficiente de atenuação linear total e a densidade $(\rho)$ do material, para resolver este problema de dependência com o estado físico ou forma alotrópica do material (Attix, 1986).

\subsection{Interação de Nêutrons com a matéria}

O nêutron é bastante penetrante em relação às outras radiações ionizantes, já que tem uma massa não muito grande e não possui carga elétrica, portanto, interage facilmente com o núcleo atômico. Os nêutrons podem ser classificados de acordo com a sua energia (Attix, 1986), como é mostrado na TAB.1:

TABELA 1: Classificação dos nêutrons segundo a sua energia (Attix, 1986).

\begin{tabular}{rc}
\hline Classificação do Nêutron & Energia do Nêutron (MeV) \\
\hline Nêutrons Térmicos & $2,5 \times 10^{-8}$ \\
Nêutons Intermediários & $4 \times 10^{-7}-1 \times 10^{-1}$ \\
Nêutrons Rápidos & $1 \times 10^{-1}-2 \times 10^{1}$ \\
Nêutrons Relativísticos & $>2 \times 10^{1}$ \\
\hline
\end{tabular}

A interação do nêutron com a matéria consiste em dois processos: espalhamento ou captura. A grandeza física que descreve se o nêutron será capturado ou espalhado é a secção de choque macroscópica, que é definida como a probabilidade, por unidade de comprimento, do nêutron ser capturado ou espalhado (Tauhata et al, 2003).

\subsubsection{Espalhamento}

O espalhamento, devido à interação dos nêutrons com a matéria, pode ser subdividido em elásticos e inelásticos. Nos espalhamentos elásticos, os nêutrons interagem com material de número atômico alto sem a perda de energia cinética, há 
apenas um desvio de trajetória. Enquanto nos espalhamentos inelásticos, os nêutrons interagem com o material de número atômico baixo transferindo uma parte de sua energia cinética para eles, podendo ativar o núcleo (Attix, 1986).

\subsubsection{Captura}

A captura neutrônica ou captura térmica é um tipo de reação nuclear que o nêutron colide com um núcleo atômico e se combinam para formar um núcleo mais pesado. A condição principal para que o nêutron combine com o núcleo atômico é que a sua energia cinética se torne comparável com a energia térmica de vibração do núcleo atômico. Existem dois processos de captura neutrônicas: processo $r$, em que há capturas múltiplas de nêutrons, e processo $\mathrm{s}$, em que há somente uma captura de nêutron (Attix, 1986).

As reações nucleares envolvendo nêutrons podem ser do tipo $(n, \alpha),(n, y)$ e $(n, n)$, em que um dos produtos de cada tipo de reação é partícula alfa, radiação gama e nêutrons, respectivamente.

\subsection{Dosimetria das radiações}

A dosimetria é a quantificação da dose absorvida em um ponto ou volume alvo pela radiação diretamente ou indiretamente ionizante (Tenório, 2001). Suas grandezas, relações entre elas e suas unidades são regidas por instituições internacionais, a Internation Commission on Radiological Protection (ICRP), criada em 1928, promove o desenvolvimento da radioproteção, e a Internation Commission on Radiation Units and Measumerents (ICRU), fundada em 1925, estabelece as grandezas básicas e operacionais (Tauhata, 2003).

\subsection{Dosímetros}

Um dosímetro de radiação pode ser um aparelho, instrumento ou sistema que mensura ou avalia, direta ou indiretamente, as grandezas dosimétricas como a exposição, kerma, dose absorvida ou dose equivalente, ou suas derivadas no tempo (taxas), ou grandezas relacionadas com a radiação ionizante. Um dosímetro juntamente com seu leitor é considerado um sistema dosimétrico (Podgorsak, 2005). 
Os dosímetros podem ser classificados como absolutos ou padrões primários e relativos ou padrões secundários. Os dosímetros absolutos são instrumentos que determinam diretamente a dose relacionada com a radiação ionizante, portanto não necessitam ser calibrados, possuem alta qualidade metrológica, como por exemplo, câmaras de "ar livre", o sistema Fricke padrão e os calorímetros. Já os dosímetros relativos requerem ser calibrados, já que a dose medida num ponto ou volume de interesse é relacionada a uma dose dada no ponto de referência em condições padronizadas, são precisos e estáveis, como por exemplo, câmaras tipo dedal, filmes e soluções químicas. Os dosímetros relativos são classificados como de transferência, secundários e terciários (Attix, 1986).

Os dosímetros de transferência são suficientemente precisos e estáveis, e são calibrados por um dosímetro de padrão primário. Os dosímetros de transferência são usados para calibração de dosímetros de rotina ou secundário e podem ser usados como dosímetros secundários. Já os dosímetros secundários são sistemas padronizados usados rotineiramente em instalações de irradiação, sendo necessária a calibração por um dosímetro de referência. Os dosímetros terciários são utilizados quando é apenas necessário estimar a dose absorvida em um determinado meio, portanto não são precisos (Attix, 1986).

\subsection{Dose Absorvida}

De acordo com o ICRP (2005), dose absorvida, $D$, é definida como o quociente entre a energia média, $d \bar{\varepsilon}$, depositada pela radiação ionizante em um elemento de volume pela massa, $d m$, deste elemento. É uma grandeza física fundamental, que é usada para todos os tipos de radiação ionizante, para qualquer meio, e para qualquer geometria de radiação, e é dado pela EQ.4:

$$
D=\frac{d \bar{\varepsilon}}{d m}
$$

A unidade desta grandeza no Sistema Internacional, SI, é Joule por quilograma, J. $\mathrm{kg}^{-1}$, denominada Gray (Gy), mas há outra unidade, ainda que antiga, 
utilizada para a medida de dose absorvida, que é a unidade inglesa rad. A correspondência entre as unidades Gray e rad é:

$$
1 \mathrm{~Gy}=100 \mathrm{rad}
$$

Para avaliar a dose total em um volume constituído por diferentes meios, e cada meio submetido a uma dose diferente, define-se a grandeza dose absorvida média (Durham, 2007), dado pela EQ.5:

$$
D_{T}=\frac{\int_{m T} D d m}{m T}
$$

Onde:

$D_{T}$ : é a dose total;

$m T$ : é a massa total no tecido;

$d m$ : é o incremento de massa;

$D$ : é a dose neste incremento.

A variação de dose $(d D)$ em um determinado tempo $(d t)$ é avaliada pela grandeza taxa de dose $(\dot{D})$, como é mostrada na EQ.6:

$$
\dot{D}=\frac{d D}{d t}
$$

A unidade da grandeza taxa de dose é Gray por segundo (Gy/s).

\subsection{Propriedades Dosimétricas}

Para que um material possa ser empregado com êxito na dosimetria das radiações, ele deve possuir propriedades dosimétricas como:

-Linearidade entre resposta do sinal e dose absorvida;

-Estabilidade;

-Boa reprodutibilidade. 


\subsubsection{Linearidade}

Para que o dosímetro seja de fácil empregabilidade, a sua sensibilidade deve ser constante em um dado intervalo de dose absorvida, pois assegura que a resposta seja linear dentro dos limites estabelecidos, consequentemente, facilitando os cálculos e a interpretação dos resultados.

Estes limites, denominados de inferior e superior, são estabelecidos de acordo com as limitações do próprio aparelho utilizado nas leituras para certas condições ou condições externas ao instrumento, causadas, em geral, pelo ruído de outras fontes e a não linearidade entre a resposta do sinal e a dose absorvida.

O limite mínimo de detecção pode ser calculado empregando a EQ.7:

$$
L I D=\left(D Q_{(0)}+3 \sigma_{D Q(0)}\right) \cdot f
$$

Onde: $D Q_{(0)}$ é a leitura média dos dosímetros não-irradiados;

$\sigma_{D Q(0)}$ é o desvio-padrão da medida dos dosímetros não-irradiados;

$f$ é o fator de calibração ou o coeficiente angular da reta ajustada.

\subsubsection{Estabilidade}

A variação ou não da resposta do dosímetro entre o tempo em que foi irradiado e o momento da leitura, é denominado de estabilidade. Este fator é principalmente influenciado pelas condições ambientais, como temperatura e umidade, por isso o dosímetro deve ser o mais insensível possível às mudanças extremas destas condições, ou permita a correção dos erros provocados por estas condições.

\subsubsection{Reprodutibilidade}

Outra característica indispensável para qualquer dosímetro é a reprodutibilidade, que está associada à precisão. Um bom dosímetro deve ser reprodutível para as mesmas condições de análise. 
Precisão mostra a dispersão dos valores medidos, e é obtida através do desvio-padrão de uma série de repetições da mesma análise. Quanto menor o desvio-padrão, maior a precisão, consequentemente, maior é a reprodutibilidade.

Uma medida pode ser precisa, mas não necessariamente exata, já que exatidão é o quão o valor experimental esta próximo do valor verdadeiro. A diferença entre o valor experimental e o valor verdadeiro é denominada de erro, ou seja, quanto menor o erro, maior é a exatidão da medida.

\subsection{Influência de Fatores Externos na Dosimetria das Radiações}

A padronização de sistemas dosimétricos é indispensável, já que a medida da dose absorvida não é direta e tecnicamente simples. Por isso, a implantação de um controle de qualidade aceito internacionalmente tornou-se necessária. Entretanto, há uma série de fatores que não são controlados facilmente como:

- dependência energética;

- taxa de dose;

- condições ambientais;

\subsubsection{Dependência Energética}

É a variação ou não da resposta do sinal para diferentes energias. Isso acarreta incertezas nos resultados medidos, caso as medidas não sejam realizadas em condições exatamente iguais àquelas postuladas para sua calibração e apresentem uma dependência energética.

\subsubsection{Taxa de Dose}

De forma análoga à grandeza dependência energética, a variação da taxa de dose provoca incertezas nos resultados medidos, caso as medidas não sejam realizadas em condições especificadas para sua calibração e apresentem uma dependência da variação com a taxa de dose. 


\subsubsection{Condições Ambientais}

A temperatura, concentração de oxigênio, difusão, iluminação, dentre outros, são condições ambientais que influenciam, principalmente, a dosimetria química, já que as reações químicas são mecanismos dinâmicos e, facilmente, dependentes destas condições, portanto, uma variação de alguma delas influencia diretamente a velocidade desta reação, culminando na variação da concentração de determinados reagentes e produtos.

\subsection{Aminoácidos}

Todo composto orgânico que apresenta simultaneamente um grupo carboxílico $(\mathrm{COOH})$ e um grupo amina $\left(\mathrm{NH}_{2}\right)$ é chamado de aminoácido. Os aminoácidos podem ser classificados de acordo com (Alencastro et al, 1978; Allinger et al, 1976; Campos, 1980; Moraes, 1976):

- A posição do grupo funcional amina: alfa-aminoácido, beta-aminoácido e gama-aminoácido;

- A capacidade do organismo de sintetizar ou não os aminoácidos a partir dos carboidratos: essenciais (sintetizado pelo organismo) e não-essenciais (não é sintetizado pelo organismo).

Os aminoácidos podem ser obtidos naturalmente ou sinteticamente. Os processos químicos que podem ser obtidos sinteticamente são (Griffin JR et al, 1970; Moraes, 1976):

- Hidrólise de proteínas;

- Síntese de Gabriel;

- Síntese de Strecker;

- Aminólise ácidos alfa-halogenados.

\subsection{DL-Alanina}

O aminoácido DL-Alanina é uma mistura de L-Alanina e D-Alanina em quantidades iguais, ou seja, uma mistura racêmica de dois enantiomorfos. Estes dois enantiomorfos são substâncias opticamente ativas. A D-Alanina é uma substância 
com isomeria óptica dextrógira, ou seja, quando é incidida luz polarizada nesta substância, ela desvia no sentido horário o plano de polarização da luz. Enquanto a L-Alanina é uma substância com isomeria óptica levógira, ou seja, quando é incidida luz polarizada nesta substância, ela desvia no sentido anti-horário o plano de polarização da luz. Como a mistura é equimolar, a DL-Alanina é uma substância opticamente inativa (Griffin JR, 1970; Moraes, 1976; Greenstein et al, 1986; Solomons, 1994; Burice, 1998).

\subsubsection{Interação da radiação com a DL-Alanina}

A DL-Alanina é um composto diamagnético, pois o momento magnético líquido total dos spins é nulo devido ao número par de elétrons contidos no composto. Quando incide radiação ionizante na DL-Alanina, ocorre a quebra das ligações covalentes em duas partes paramagnéticas com um elétron desemparelhado em cada uma, resultando em radicais livres (Griffin, 1970; Campos, 1980; Greensteinst et al, 1986; Costa, 1994). Dentre os radicais livres produzidos através das reações de deaminação da DL-Alanina induzidas pela radiação, a espécie mostrada abaixo é predominante à temperatura ambiente (Costa, 1994; Zargóski, 1998; Galante, 2000).

$$
\mathrm{CH}_{3}-\dot{\mathrm{C}} \mathrm{H}-\mathrm{COOH}
$$

\subsection{Dosimetria Química}

A dosimetria química consiste na determinação da dose absorvida através da medida da variação das concentrações dos reagentes químicos presentes na solução, induzidos pela radiação ionizante. Quando a radiação interage com um meio, esta pode ser convertida na produção de íons. Os íons podem favorecer reações com outras moléculas, produzindo radicais livres e íons secundários, que podem reagir e formar produtos químicos estáveis (Gay et at, 1999; Palm et al, 2000).

Em 1927, Hugo Fricke e Stern Morse (1927) iniciaram um estudo sobre a ação química de uma solução de sulfato ferroso para realizar medidas de dose 
absorvida para raios $\mathrm{X}$, de forma que a resposta fosse a mesma que a câmara de ionização (Anderson, 1993), surgindo a Dosimetria Química. Em 1929, Hugo Fricke foi o precursor do sistema Fricke, que é baseado na oxidação do íon ferroso, Fe-II, em íon férrico, Fe-III, na presença de oxigênio, sob influência da radiação ionizante. As principais reações envolvidas são:

$$
\begin{aligned}
& \mathrm{Fe}^{2+}+\mathrm{OH}^{\bullet} \rightarrow \mathrm{Fe}^{3+}+\mathrm{OH}^{-} \\
& \mathrm{H}^{\cdot}+\mathrm{O}_{2} \rightarrow \mathrm{HO}_{2}{ }^{-} \\
& \mathrm{Fe}^{2+}+\mathrm{HO}_{2} \rightarrow \mathrm{Fe}^{3+}+\mathrm{HO}_{2}^{-} \\
& \mathrm{HO}_{2}^{-}+\mathrm{H}^{+} \rightarrow \mathrm{H}_{2} \mathrm{O}_{2} \\
& \mathrm{Fe}^{+2}+\mathrm{H}_{2} \mathrm{O}_{2} \rightarrow \mathrm{Fe}^{3+}+\mathrm{OH}^{-}+\mathrm{OH}^{\bullet}
\end{aligned}
$$

Cada átomo de hidrogênio forma um radical hidroperóxido, $\mathrm{HO}_{2}$, e cada um destes radicais oxidam três íons de $\mathrm{Fe}^{2+}$, um através da reação (III) e dois através das reações (IV), (V) e (I). Cada radical hidroxila oxida um íon de $\mathrm{Fe}^{2+}$ e cada molécula de peróxido de hidrogênio oxida dois íons de $\mathrm{Fe}^{2+}$. Todas as reações, exceto a (V) são rápidas.

A presença de impurezas orgânicas causa variação significativa na resposta deste dosímetro, por este motivo é essencial utilizar compostos muito puros.

Com base no sistema químico Fricke, foram estudados outros materiais com o propósito de alcançar uma praticidade, precisão e acurácia cada vez maior. Com isso surgiram os materiais em forma de gel: Fricke Gel (Gore et al, 1984; Bero, 2001; Cavinato, 2006 e 2007; Galante et al, 2008), Geís Poliméricos (Maryanski, 1994; Fong, 2001; Baffa et al, 2006) e Alanina Gel (Mizuno, 2007).

Em 1984, a Dosimetria Gel foi introduzida por Gore, que combinou o dosímetro Fricke com a técnica de Ressonância Magnética Nuclear (RMN) (Gore et al, 1984; Schreiner, 2004). Os íons ferrosos, Fe-II, e os íons férricos, Fe-III, presentes no sistema dosimétrico, possuem elétron com o estado de spin paramagnético e raios iônicos diferentes, conseqüentemente, uma taxa de relaxação spin-spin dos prótons da água diferentes. Por meio desta diferença é produzido o 
contraste das imagens por ressonância magnética (IRM) (Geoffrey, 2006). As vantagens deste sistema são que a química das radiações é bem descrita e compreendida, são materiais tecido equivalente para efeito da interação da radiação com a matéria e os processos relacionados ao sistema aquoso e a técnica por IRM também são compreendidas (Schreiner, 2004). Entretanto, foi mostrado que o sistema Fricke gel não mantem a distribuição de dose estável espacialmente, já que há difusão dos íons dentro do gel irradiado, tornando este problema algo significante para o avanço da dosimetria gel (Schulz et al, 1990).

Em 1992, um novo gel dosimétrico foi proposto, o qual combina a polimerização e o cross linking dos monômeros acrilamida e N,N'- acrilamida-bismetileno (bis) com uma matriz de agarose aquosa, conhecido pelo acrônimo BANANA, devido ao uso dos componentes químicos escrito em língua inglesa (bis, acrylamide, nitrous oxide e agarose) (Maryanski et al, 1994). Este novo sistema não tem a mesma limitação que o sistema Fricke gel, mas possui outras limitações. Requer um ambiente atmosférico controlado e seus componentes químicos são tóxicos, o que torna inviável na introdução no ambiente clínico (Baldock, 2006). Fong desenvolveu em 2001, um novo tipo de dosímetro gel de polímero, a estrutura do gel é tal que as regiões polimerizadas são inerentemente fixas e o problema da difusão não existe (Doran, 2009), mas persiste o problema dos componentes químicos tóxicos (Fong et al, 2001).

Em 2007, Mizuno et al (2007) desenvolveu um novo material em forma de gel, que apresentou uma melhora significante em relação ao sistema a base de Alanina desenvolvido por Costa (1994). O principio de funcionamento é baseado na transformação de íons ferrosos $\left(\mathrm{Fe}^{2+}\right)$ em íons férricos $\left(\mathrm{Fe}^{3+}\right)$ induzidos pela radiação ionizante. Os íons ferrosos e férricos correspondem aos comprimentos de onda de 457 e 585 nm, respectivamente, no espectro de absorção que é mostrado na FIG.2. Os radicais formados pela interação da radiação com os componentes químicos da solução oxidam os íons ferrosos em íons férricos, estes combinados com o Alaranjado de Xilenol formam um complexo de tonalidade diferente da solução inicial, sendo que a tonalidade depende da dose absorvida no meio, como pode ser observado na FIG.3. O papel da Alanina é melhorar a produção dos íons férricos, já 
que os radicais formados pela interação da radiação também oxidam os íons ferrosos (Gupta, B.L., 1982; Gupta, B.L et al, 1985; Gupta, B.L et al, 1986) (Van Bree, 1994; Gay, 1999; Van Laere et al, 1989a, 1989b). É possível avaliar a dose absorvida com as técnicas de Absorção Óptica (AO) e IRM.

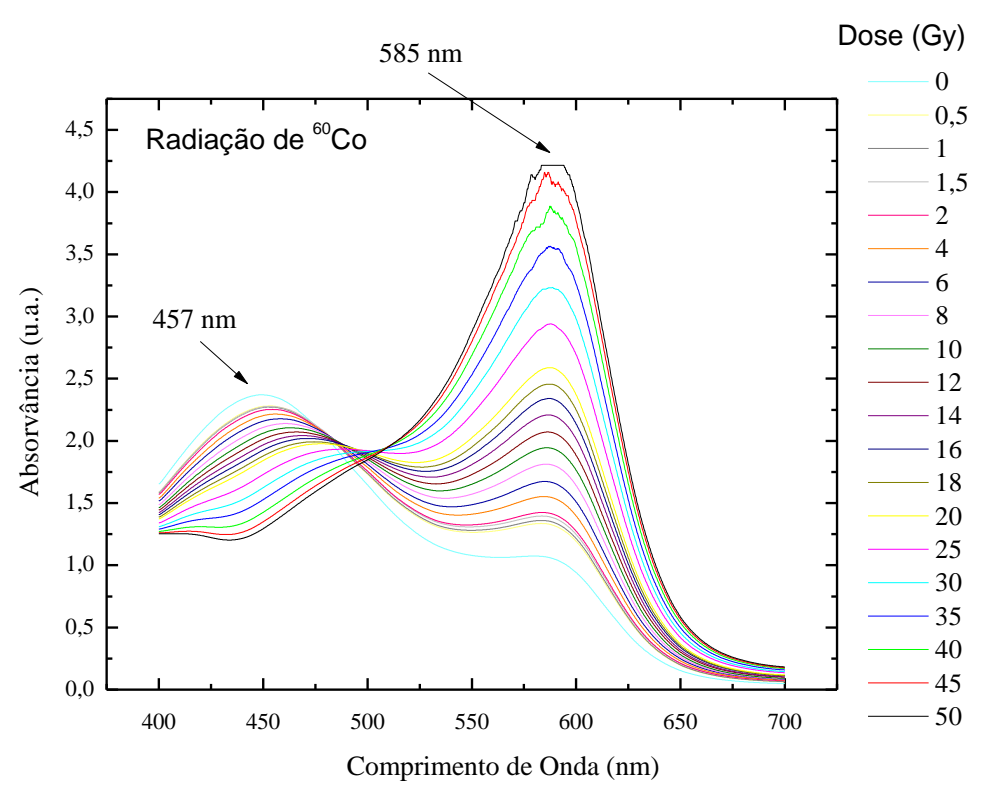

FIGURA 2: Espectro de Absorção da solução gel de Alanina para radiação de ${ }^{60} \mathrm{Co}$.

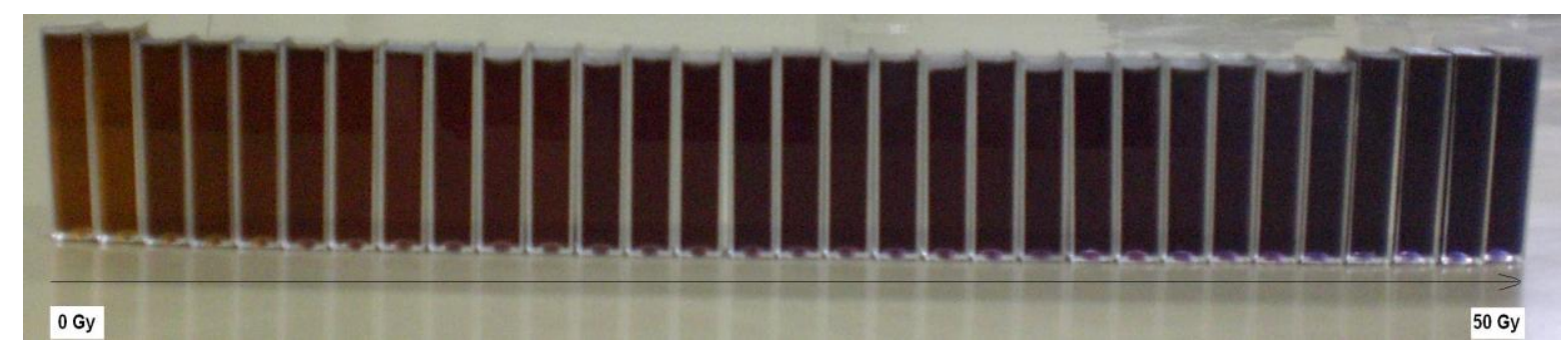

FIGURA 3: Variação da tonalidade da solução gel de Alanina em função da dose.

A Alanina é amplamente utilizada, tanto como um dosímetro de referência ou padrão secundário, pois é preciso e estável, além de ser tecido equivalente para efeitos da interação da radiação com a matéria (IAEA, 1994), e como dosímetro padrão para doses em nível industrial (Galante,1999). Por isso a escolha deste aminoácido para o desenvolvimento de um dosímetro. 


\subsection{Aplicações da Dosimetria Química em forma de gel}

Atualmente, como escrito anteriormente, os métodos dosimétricos convencionais disponíveis não apresentam caráter tridimensional (Horowitz, 1994; Moraes, 2006), por isso a Dosimetria Química com materiais em forma de gel tornouse um instrumento muito útil para a verificação dos tratamentos de radiação em tecidos equivalentes à água, já que é extremamente importante determinar a distribuição tridimensional da dose absorvida nos pontos de interesse.

\subsubsection{Radioterapia}

Os raios $X$ e gama induzem danos em profundidades diversas do organismo do seres vivos culminando na morte de células, portanto podem ser aplicados na terapia contra o câncer. Tumores profundos podem ser destruídos ou regredidos sob a ação de feixes de radiação adequadamente aplicada (Tauhata et al, 2003).

Para certos tumores localizados em determinadas regiões do corpo humano podem ser inseridas fontes de radiação no local onde se localiza o tumor, esta técnica é chamada de Braquiterapia (Tauhata et al, 2003).

Nestes casos, pode ser aplicada a dosimetria gel para avaliar tridimensionalmente a dose absorvida nos tecidos.

\subsubsection{Radiocirurgias}

Radiocirurgia é uma cirurgia não-invasiva realizada por meio de feixes direcionados de radiação ionizante. Esta técnica forneceu meios alternativos para os médicos tratarem pacientes com tumor de cérebro e outros tipos de tumores, com deposição de dose baixa ao redor de tecidos sadios (Gambarini et al, 1997), que não podem ser efetivamente tratados pelos procedimentos convencionais de terapia com radiação (Gambarini et al, 2002). 


\subsubsection{Gamma Knife}

Gamma Knife ou Leksell Gamma Knife, já que foi inventado por Lars Leksell, é um instrumento utilizado para tratamento de tumores cerebrais com uma dose alta de radiação gama em uma única aplicação.

O dispositivo é constituído por 201 fontes de cobalto-60, com atividade de aproximadamente $30 \mathrm{Ci}(1,1 \mathrm{TBq})$, colocadas em um arranjo semi-circular blindado, direcionando o feixe de radiação para um ponto-alvo localizado no cérebro, poupando relativamente as demais regiões em torno do ponto-alvo (Dong et al, 1996). Veja FIG.4:

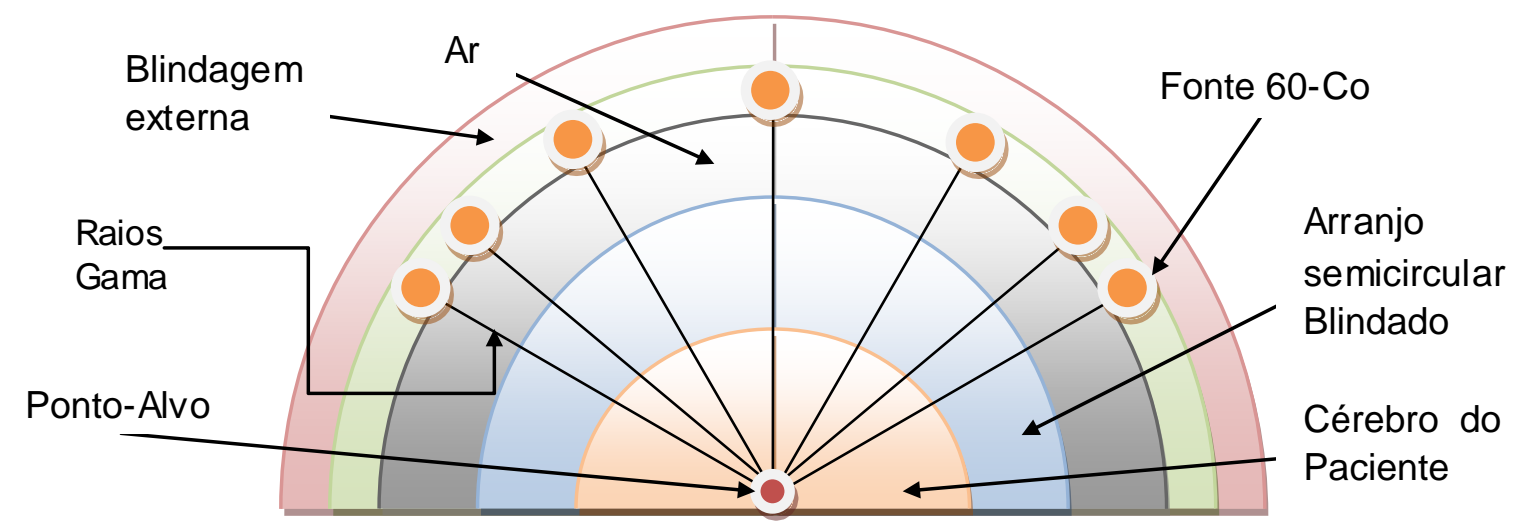

FIGURA 4: Esquema do instrumento Gamma-Knife.

O material em forma de gel é usado no mapeamento de toda a região em que será irradiado o cérebro do paciente, permitindo analisar a distribuição de dose absorvida antes da irradiação propriamente dita, ou seja, permiti a simulação.

\subsubsection{Terapia de Captura de Nêutrons com Boro}

Terapia de Captura de Nêutrons com Boro ou BNCT (sigla em inglês) é um tipo de radiocirurgia usada para os tratamentos de tumor no cérebro o qual depende da interação de nêutrons lentos com o isótopo ${ }^{10} \mathrm{~B}$ injetado no tumor para produzir partículas alfas.

$\mathrm{O}{ }^{10} \mathrm{~B}$ possui uma secção de choque alta para nêutrons térmicos, aumentando a relação dose tumor/tecido sadio. Os produtos da reação quando ${ }^{10} \mathrm{~B}$ é 
irradiado com nêutrons são o átomo de Lítio (um em um estado excitado e o outro em estado fundamental) e a partícula alfa, a probabilidade de ocorrência e o $Q$-value (massas de repouso dos núcleos envolvidos na reação) são mostrados na TAB.2.

TABELA 2: Dados envolvidos nas reações de ${ }^{10} \mathrm{~B}$ com nêutrons.

\begin{tabular}{cccc}
\hline Reação & $\begin{array}{c}\text { Produtos da } \\
\text { Reação }\end{array}$ & Q (MeV) & $\begin{array}{c}\text { Probabilidade de } \\
\text { Ocorrência (\%) }\end{array}$ \\
\hline${ }_{5}^{10} B+{ }_{0}^{1} n \rightarrow$ & ${ }_{3}^{7} L i+{ }_{2}^{4} \alpha$ & 2,792 & 6 \\
& ${ }_{3}^{7} L i *+{ }_{2}^{4} \alpha$ & 2,310 & 94 \\
\hline
\end{tabular}

* Átomo excitado.

Nesta técnica pode ser usada a dosimetria gel para determinar a distribuição de dose absorvida no volume irradiado.

\subsubsection{Acelerador Linear}

Os aceleradores lineares médicos são aceleradores cíclicos que aceleram elétrons com energias cinéticas entre 4 a $25 \mathrm{MeV}$, usando campos de radiofreqüência $(\mathrm{RF})$ de microondas não-conservativos, com frequências variando entre $10^{3}$ e $10^{4} \mathrm{MHz}$, sendo que a maioria dos aceleradores operam na frequência de $2856 \mathrm{MHz}(\mathrm{IAEA}, 2000)$.

Os elétrons são acelerados através de guias de ondas seguindo trajetória retilínea desde a fonte. As guias de ondas geram uma diferença de potencial em que os elétrons são submetidos por várias vezes. A potência alta dos campos de radiofrequência usados para acelerar os elétrons nas guias de onda, que constituirão o feixe de energia alta, é produzida pelo processo de desaceleração de elétrons em potenciais de retardo através de instrumentos especiais chamado de magnetron ou klystron. Estes processos são realizados a vácuo no acelerador (Podgorsak, 2005).

Existem vários tipos de aceleradores lineares disponíveis para uso clínico. Alguns geram apenas feixes de raios $X$ no intervalo de baixa voltagem, 4 ou $6 \mathrm{MV}$. Enquanto outros geram também feixes de raios $X$ e elétrons, porém com várias energias de megavoltagem. Um típico acelerador linear clínico de energia alta gera 
feixes de fótons, com duas energias de megavoltagem (6 e $18 \mathrm{MV}$ ), e de elétrons, com várias energias.

Durante 40 anos, os aceleradores passaram por 5 gerações diferentes, que é apresentada a seguir (Podgorsak, 2005):

- Fótons de energia baixa (4 a $8 \mathrm{MV}$ );

- Fótons de energia média (10 a $15 \mathrm{MV}$ );

- Fótons de energia alta (18 a $25 \mathrm{MV}$ );

- Fótons e elétrons de energia alta;

- Fótons e elétrons de energia alta, com feixe de fótons com intensidade modulada por um colimador multi-lâmina estático (CML).

\subsubsection{Terapia de Radiação com Intensidade Modulada (TRIM)}

A TRIM utiliza colimadores multi lâmina que pode ligar ou desligar ou serem bloqueados durante o tratamento, variando a intensidade em todo o feixe de radiação orientada pelo campo, isso significa uma distribuição de dose conformal mais precisa em torno de tumores ou áreas específicas dentro do tumor, já que permite moldar de forma aproximada o tumor (Grégoire et al, 2007).

Os feixes de radiação podem ser movidos dezenas ou centenas de vezes e cada um pode ter uma intensidade diferente, resultando em radiação esculpida em três dimensões. O tecido saudável circundante recebe uma dose menor, enquanto o tumor recebe uma dose elevada que pode variar dentro do tumor (Teh et al, 1999).

O gel dosimétrico pode ser utilizado para verificar se a distribuição de dose tridimensional foi aplicada corretamente.

\subsubsection{Dosimetria 2D pela Técnica de Absorção Óptica (AO)}

O sinal óptico é avaliado através da técnica de espectrofotometria, que é baseada na transmissão ou absorção de comprimentos de onda com energias que variam continuamente na faixa do visível ao ultravioleta pelo meio que deseja analisar (Gupta, B.L., 1982; Gupta, B.L et al, 1985 e 1986). A técnica de AO é regida pela lei de Beer-Lamber, EQ.8: 


$$
A=-\log \frac{I}{I_{0}}
$$

Onde:

A : Absorvância ou densidade óptica;

$I:$ Intensidade óptica transmitida na amostra irradiada;

$I_{0}$ : Intensidade óptica transmitida na amostra não-irradiada.

A interação da radiação com o gel dosimétrico a base de íons ferrosos induz a ionização e consequentemente a formação de centros de cor. Os centros de cor são resultados de recombinações dos radicais formados com os íons ferrosos e também com os íons férricos, sendo que os íons associados aos radicais possuem cores características diferentes, o que permite avaliar com a técnica espectrofotometria.

\subsubsection{Dosimetria 3D pela Técnica de Imagemamento por Ressonância Magnética (IRM)}

Mudanças na concentração de íons férricos podem ser detectadas pela técnica de ressonância magnética Nuclear (RMN) de prótons, porque a conversão de íons ferrosos em férricos em meio aquoso altera o tempo de relaxação $\mathrm{RMN}$ da solução. Os íons $\mathrm{Fe}^{2+}$ e $\circ \mathrm{Fe}^{3+}$ são espécies paramagnéticas que podem reduzir drasticamente o tempo de relaxação do próton da água, quando presentes, mesmo em pequenas concentrações. Os tempos de relaxação $T_{1}$ e $T_{2}$ do núcleo do hidrogênio em solução aquosa são determinados pela intensidade e espectro de freqüência do campo magnético dependente do tempo afetado por cada núcleo (Abragan, 1961). Esses campos locais flutuantes são modulados pelo movimento molecular randômico dentro do fluído. A fonte dominante de interações magnéticas na água pura é o acoplamento dipolo - dipolo entre os núcleos de $\mathrm{H}$ na mesma molécula ou entre moléculas vizinhas. O forte efeito dos íons de metais de transição nas taxas de relaxação é devido, principalmente, ao largo campo local produzido pelos spins dos elétrons desemparelhados que dão origem ao seu paramagnetismo. O momento magnético do elétron é 658 vezes maior que o do próton, tal que as 
interações de relaxação dominantes ocorrem quando os prótons estão próximos dos íons dissolvidos. Mesmo para concentrações menores que $1 \mathrm{mM}$, a taxa de relaxação é dominada pelas espécies paramagnéticas.

A habilidade para aumentar as taxas de relaxação RMN é específica para cada íon ou radical paramagnético. Ela depende do momento magnético das espécies e do raio iônico, uma vez que esses determinam a intensidade do campo magnético local afetado pelos spins dos prótons. Um terceiro importante fator é o tempo de relaxação do spin do elétron $t_{s}$, o qual descreve a escala de tempo do campo flutuante produzido pelo elétron desemparelhado. A teoria detalhada de relaxação de spin induzida por íons paramagnéticos em soluções aquosas foi desenvolvida por Solomon (1955) e Bloembergen et al (1961).

Os métodos e equipamentos de IRM desenvolvidos nos últimos anos para o diagnóstico médico por imagem podem ser usados para avaliar os simuladores (phantons) irradiados e registrar a distribuição espacial da dose.

Gore notou a conhecida diferença na contribuição à relaxação RMN da água pelos íons $\mathrm{Fe}^{2+}$ e $\mathrm{Fe}^{3+}$, e usou essa propriedade. Todavia, um problema do uso de íons $\mathrm{Fe}^{3+}$ como marcador para dose de radiação, é que eles são pequenos e altamente móveis. Isso significa que a determinação da dose absorvida é afetada pelo processo de difusão.

Esse conceito geral pode ser implementado na prática de diferentes modos, empregando diferentes propriedades RMN sensíveis à radiação dos diferentes materiais.

Os mais simples empregam dosímetros químicos com a solução de sulfato ferroso para a determinação da dose e da distribuição da dose e desenvolveram simuladores de diferentes materiais e formas (Baras et al, 2002; Chu et al, 2001; Silva et al,2003).

No IPEN foram desenvolvidos dosímetros químicos em forma de gel para serem usados também na determinação da dose e da distribuição da dose, como o Fricke Gel (Galante, 2008) e a Alanina Gel (Mizuno, 2007). Também foram feitos simuladores de pescoço (Mizuno, 2007), mama (Galante, 2006) e cabeça (Cavinato, 2009) empregando as técnicas de AO e IRM. 
Outros materiais tecido equivalentes na forma de gel têm sido estudados. O polímero gel $\mathrm{N}$-VinylPyrrolidone Argon (VIPAR), foi desenvolvido por Baras et al (2002) tendo apresentado resultados promissores. O FXG (Ferrous Sulphate Xylenol Orange in Gelatin Gel), uma variação do Fricke gel, também apresenta boas qualidades para aplicação na dosimetria 3D. 


\section{MATERIAIS E MÉTODOS}

\subsection{Materiais}

\subsubsection{Sistema Dosimétrico}

A composição química da solução de Alanina gel é dada pela TAB.3:

TABELA 3: Composição química da solução gel de Alanina.

\begin{tabular}{|c|c|}
\hline Composto & $\mathrm{C}(\mathrm{mol} / \mathrm{L})$ \\
\hline Sulfato Ferroso Amoniacal & 0,001 \\
\hline Xilenol & 0,0002 \\
\hline Ácido Sulfúrico & 0,2375 \\
\hline DL-Alanina & 0,6735 \\
\hline Água tri-destilada & 5,55 \\
\hline Gelatina (300 Bloom) & $10 \%$ do volume de água tri-destilada \\
\hline Tetraborato de Sódio $\left(19,9 \% \text { de }{ }^{10} \mathrm{~B}\right)^{*}$ & $3,510^{-3}\left(60 \mathrm{ppm}{ }^{10} \mathrm{~B}\right)$ \\
\hline
\end{tabular}

Todos os compostos são fabricados pelos laboratórios da MERCK, exceto a Gelatina (300 Bloom) da Sigma, o Tetraborato de Sódio da Reagen, e a água tridestilada que é obtida no laboratório de Doses Altas da Gerência de Metrologia das Radiações do IPEN. 


\subsubsection{Balança de Precisão}

Foi utilizada a balança Metler Toledo AB204-S, com precisão de até $0,0001 \mathrm{~g}$, para medir a massa dos reagentes químicos. Tomou-se o cuidado para garantir uma precisão de até $0,001 \mathrm{~g}$.

\subsubsection{Preparação do gel}

O método descrito por Mizuno (2007) foi seguido e adaptado para preparar a solução com a gelatina 300 Bloom. As etapas do método são descritas a seguir:

- Primeiramente, foram medidas as massas dos reagentes e o volume de ácido sulfúrico e água tri-destilada;

- Em um béquer foi colocado o ácido sulfúrico com a DL-Alanina, de forma que a DL-Alanina fosse completamente dissolvida;

- Foram inseridos o Xilenol, o Sulfato Ferroso Amoniacal, e a gelatina 300 Bloom, juntamente com a água tri-destilada;

- Esperou-se 10 minutos para que a gelatina fosse hidratada, após este tempo, a temperatura foi elevada a $45^{\circ} \mathrm{C}$, sob constante agitação, para que a gelatina se dissolvesse;

- Com a gelatina dissolvida, a solução foi retirada do agitador para atingir a temperatura ambiente;

- Após atingir equilíbrio térmico, a solução foi acondicionada em cubetas de acrílico $\left(1,1 \times 1,1 \times 4,6 \mathrm{~cm}^{3}\right)$ e caminho óptico de $1 \mathrm{~cm}$, com $1 \mathrm{~mm}$ de espessura, apresentada na FIG.5, e mantida em baixa temperatura (aproximadamente $5^{\circ} \mathrm{C}$ ) durante $24 \mathrm{~h}$ para solidificação;

- Antes da irradiação as amostras foram mantidas em temperatura ambiente por 30 minutos para entrar em equilíbrio térmico.

A solução foi preparada em um ambiente com temperatura aproximada de 25ํㅡ e umidade relativa de $70 \%$, sempre que era possível, já que não havia controle destes parâmetros, pois não havia instrumentos que pudesse controlá-los no laboratório. 


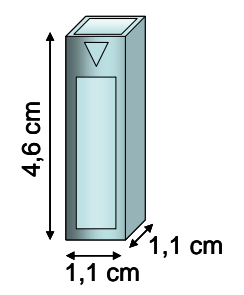

FIGURA 5: Dimensões externas da cubeta de acrílico para a leitura no espectrofotômetro.

\subsubsection{Objeto Simulador}

Objeto simulador é o nome dado a diferentes materiais que apresentam densidade, densidade eletrônica e número atômico efetivo, similares aos da água. $\mathrm{O}$ objeto simulador deve permitir o posicionamento dos dosímetros nas profundidades desejadas, profundidade de referência $\left(z_{\text {ref }}\right)$, semi-redutora $\left(R_{50}\right)$ e de máxima ionização $\left(z_{\max }\right)$, e garantir o retroespalhamento (IAEA, 2000; Maíra, 2008).

De acordo com o TRS-398 (IAEA, 2000), o dosímetro deve ser irradiado em um simulador de água, mas, em virtude das condições técnicas, não foi possível. Por isso foram confeccionadas placas de acrílico (PMMA) com $30 \times 30 \times 1,8 \mathrm{~cm}^{3}$, mostrada na FIG.6, que utilizadas conjuntamente com placas de água sólida RW3 (30 $\times 30 \mathrm{~cm}^{2}$ e diferentes espessuras) como objeto simulador para dosimetria de fótons e elétrons clínicos.

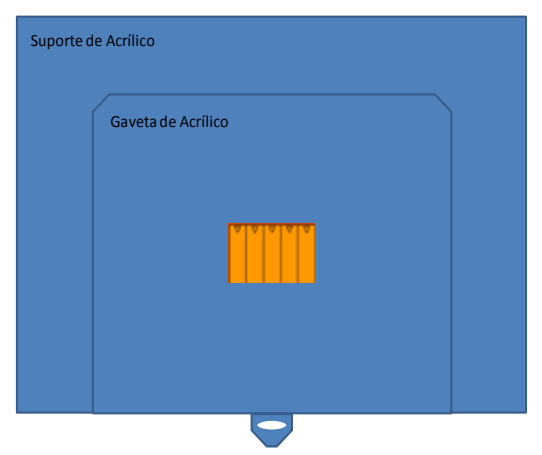

FIGURA 6: Suporte de acrílico com as cubetas no centro para a irradiação.

Nos ensaios realizados, o objeto simulador foi usado apenas para posicionar a profundidade de máxima ionização no centro da cubeta para as irradiações com elétrons e fótons de energias altas. 


\subsection{Sistemas de Irradiação}

\subsubsection{Irradiadores $4 \pi$ de ${ }^{60} \mathrm{Co}$}

Esses irradiadores são constituídos por várias fontes de ${ }^{60} \mathrm{Co}$ distribuídas em geometria $4 \pi$.

\subsubsection{Fonte Panorâmica}

A fonte Panorâmica, pertencente ao Centro de Tecnologia das Radiações, consiste em diversas fontes de ${ }^{60} \mathrm{Co}$, em forma de bastão (denominado por lápis), suspensas a partir da blindagem de chumbo que se localiza abaixo da mesa. Quando o sistema é ligado, as fontes são retiradas da blindagem e suspensas até a altura onde serão realizadas as irradiações, conforme pode ser observado na FIG.7. Este instrumento permite a irradiação de materiais em diferentes distâncias (10 e $50 \mathrm{~cm}$ ) sem o contato direto, consequentemente, com diferentes taxas de dose e evitando a contaminação.

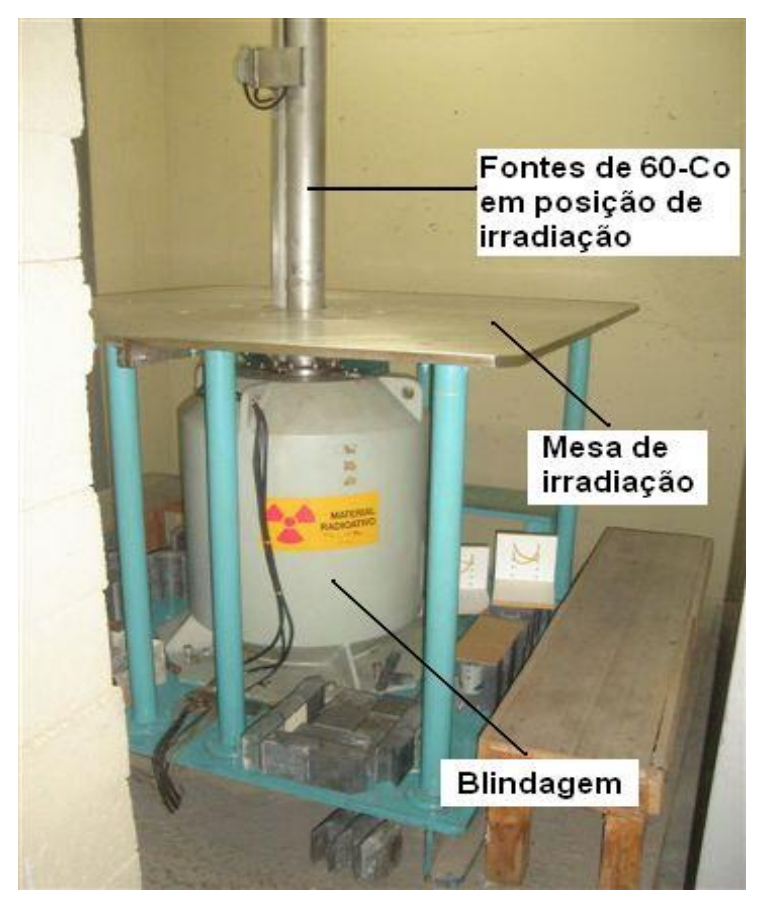

FIGURA 7: Fonte Panorâmica pertencente ao Centro de Tecnologia das Radiações/IPEN. 
Os parâmetros da fonte Panorâmica são mostrados na TAB.4:

TABELA 4: Parâmetros da fonte Panorâmica.

\section{Parâmetros}

Energia Média

Meia-Vida

Atividade (01/10/2008)

Taxa de Dose

Dose de Trânsito

Distância fonte/dosímetros
$1,25 \mathrm{MeV}$

5,27 anos

19,4 TBq $(524,295 \mathrm{Ci})$

$29,7 \mathrm{~Gy} / \mathrm{h}$

0,0804 Gy

$40 \mathrm{~cm}$

\subsubsection{Fonte Gammacell}

A fonte Gammacell, que pertencente ao Centro de Tecnologia das Radiações do IPEN, consiste em diversas fontes de ${ }^{60} \mathrm{Co}$ em forma de bastão posicionadas na periferia de uma blindagem de chumbo. Este irradiador possui um sistema cilíndrico que permite que o material seja posicionado, e quando ligado, este sistema desce permitindo a irradiação do material, sem que haja contato direto do material a ser irradiado e as fontes.

Os parâmetros do irradiador tipo Gammacell são mostrados na TAB.5:

TABELA 5: Parâmetros da fonte Gammacell.

\section{Parâmetros}

Energia Média

Meia-Vida

Atividade (01/10/2008)

Taxa de Dose

Dose de Trânsito
$1,25 \mathrm{MeV}$

5,27 anos

105,64 TBq $(2,855 \mathrm{kCi})$

$2,36 \mathrm{kGy} / \mathrm{h}$

2,04 Gy

Na FIG.8 é mostrado o irradiador tipo Gammacell utilizado. 


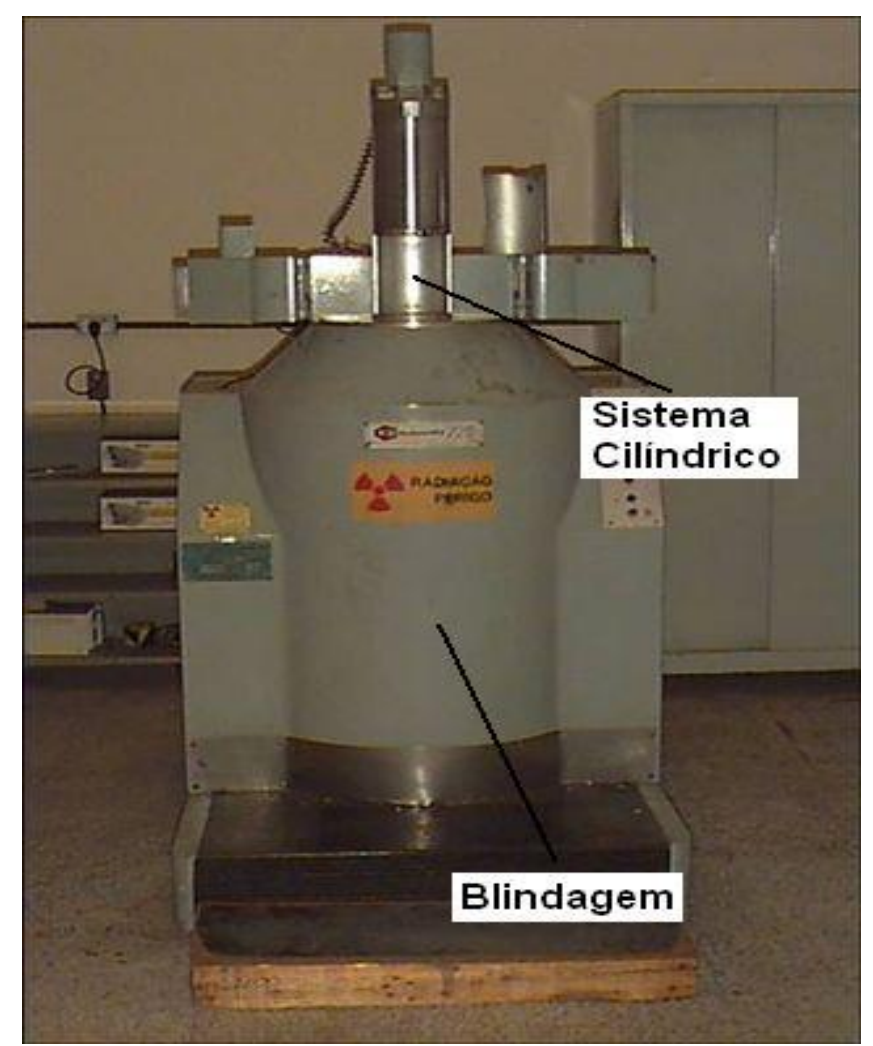

FIGURA 8: Irradiador tipo Gammacell pertencente ao Centro de Tecnologia das Radiações/IPEN.

\subsubsection{Arranjo Experimental para irradiação nos irradiadores $4 \pi$}

Para as irradiações nos irradiadores $4 \pi$, o arranjo de irradiação constou de um conjunto de 4 cubetas alojadas em uma capa de equilíbrio eletrônico com paredes de acrílico de $4 \mathrm{~mm}$ de espessura, que é material tecido-equivalente para efeitos do comportamento da penetração da radiação gama do ${ }^{60} \mathrm{Co}$.

\subsubsection{Acelerador de Elétrons Dynamitron Job 188 (Aplicações Industriais)}

O princípio de funcionamento do acelerador de elétrons Dynamiltron Job 188, pertencente ao Centro de Tecnologia das Radiações (CTR) do IPEN, consiste em um filamento que emite elétrons, estes são acelerados por uma tensão constante elevada, através de sistemas capacitivos que energizam circuitos retificadores multi-estágios, resultando em um feixe de elétrons constantes. Toda a região de produção e aceleração dos elétrons é mantida em alto vácuo, que permiti a aceleração e focalização dos elétrons em direção à janela de titânio. 
As amostras são posicionadas em bandejas, que são levadas por uma esteira até a região de irradiação, conforme pode ser observado na FIG.9:

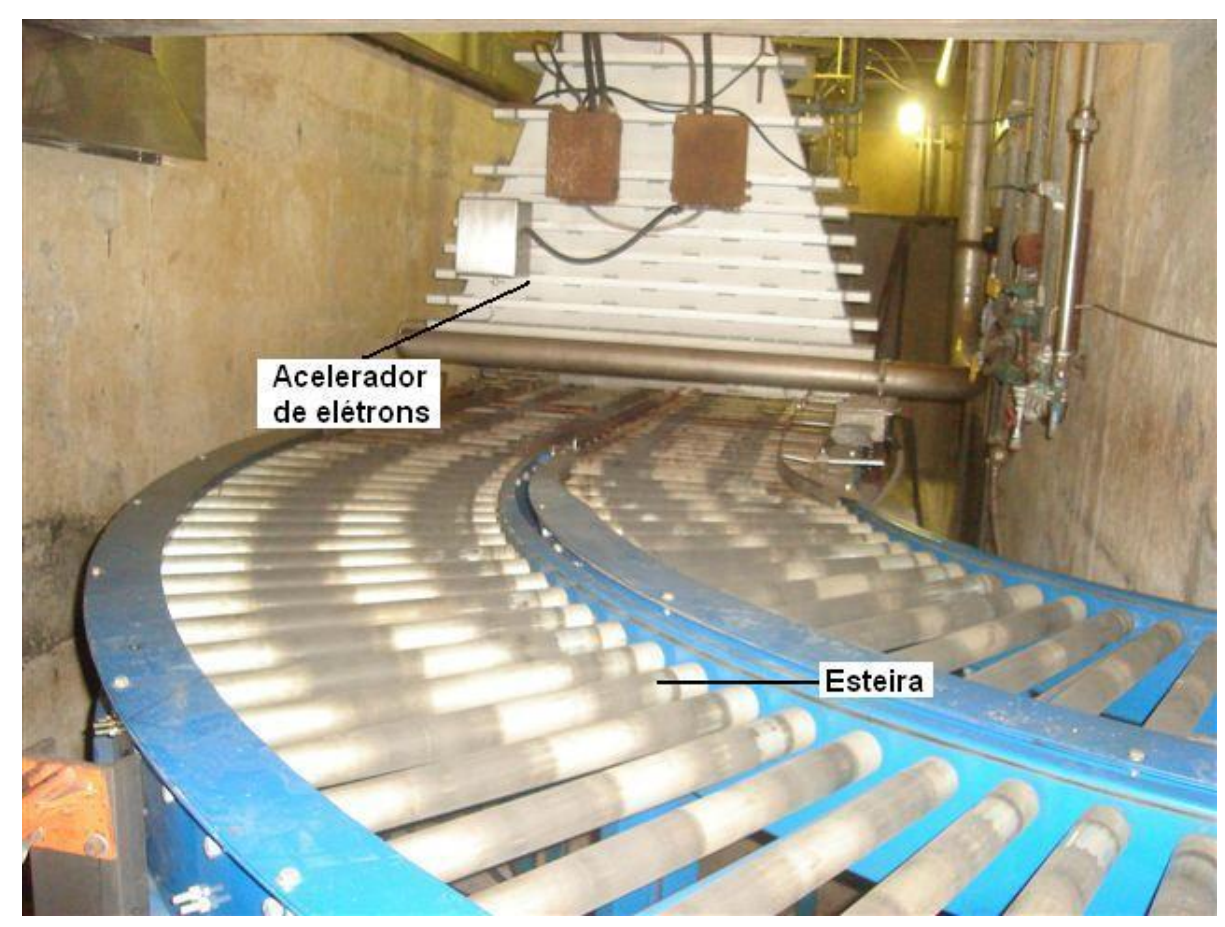

FIGURA 9: Acelerador de Elétrons Dynamiltron Job 188 pertencente ao Centro deTecnologia das Radiações/IPEN.

Os parâmetros operacionais do acelerador são apresentados na TAB.6:

TABELA 6: Parâmetros de irradiação do Acelerador de Elétrons Dynamiltron Job 188 pertencente ao Centro de Tecnologia das Radiações/IPEN.

\begin{tabular}{cc}
\hline Parâmetros & \\
\hline Energia dos Elétrons & $0,5-1,5 \mathrm{MeV}$ \\
Potência & $37,5 \mathrm{~kW}$ \\
Corrente & $0,01-25 \mathrm{~mA}$ \\
Largura de Varredura & $60-112 \mathrm{~cm}$ \\
Dose por Passada & $0,5 \mathrm{kGy}$ \\
Área de Irradiação & $0,6735 \mathrm{~cm}^{2 *}$ \\
\hline
\end{tabular}

* A $10 \mathrm{~cm}$ da janela de titânio 


\subsubsection{Acelerador Linear Clinac 2100-C Varian (Aplicações Clínicas)}

As irradiações com feixes clínicos de fótons e elétrons foram realizados empregando um acelerador linear modelo Clinac 2100-C Varian.

Os parâmetros de irradiação estão relacionados na TAB.7 para os feixes de fótons e elétrons produzidos pelo acelerador linear modelo Clinac 2100-C Varian pertencente ao Hospital das Clínicas com a profundidade de máxima dose.

TABELA 7: Parâmetros de irradiação do acelerador linear clinac 2100-C da Varian.

\begin{tabular}{cccc}
\hline \multicolumn{2}{c}{ Fótons } & \multicolumn{2}{c}{ Elétrons } \\
\hline $\begin{array}{c}\text { Energia Nominal } \\
(\mathrm{MeV})\end{array}$ & $\begin{array}{c}\text { Profundidade de } \\
\text { Máxima Dose }(\mathrm{cm})\end{array}$ & $\begin{array}{c}\text { Energia Nominal } \\
(\mathrm{MeV})\end{array}$ & $\begin{array}{c}\text { Profundidade de } \\
\text { Máxima Dose }(\mathrm{cm})\end{array}$ \\
\hline 6 & 1,5 & 6 & $1,2-1,4$ \\
15 & 2,9 & 9 & $1,8-2,2$ \\
& & 12 & $2,5-3,1$ \\
& 15 & $2,6-3,6$ \\
\hline
\end{tabular}

O campo de radiação utilizado foi um campo de $10 \times 10 \mathrm{~cm}^{2}$ tanto para fótons como para elétrons, com placas de água sólida em cima e embaixo do suporte de acrílico para garantir a profundidade desejada e o retroespalhamento, respectivamente. O esquema de irradiação é mostrado na FIG.10: 


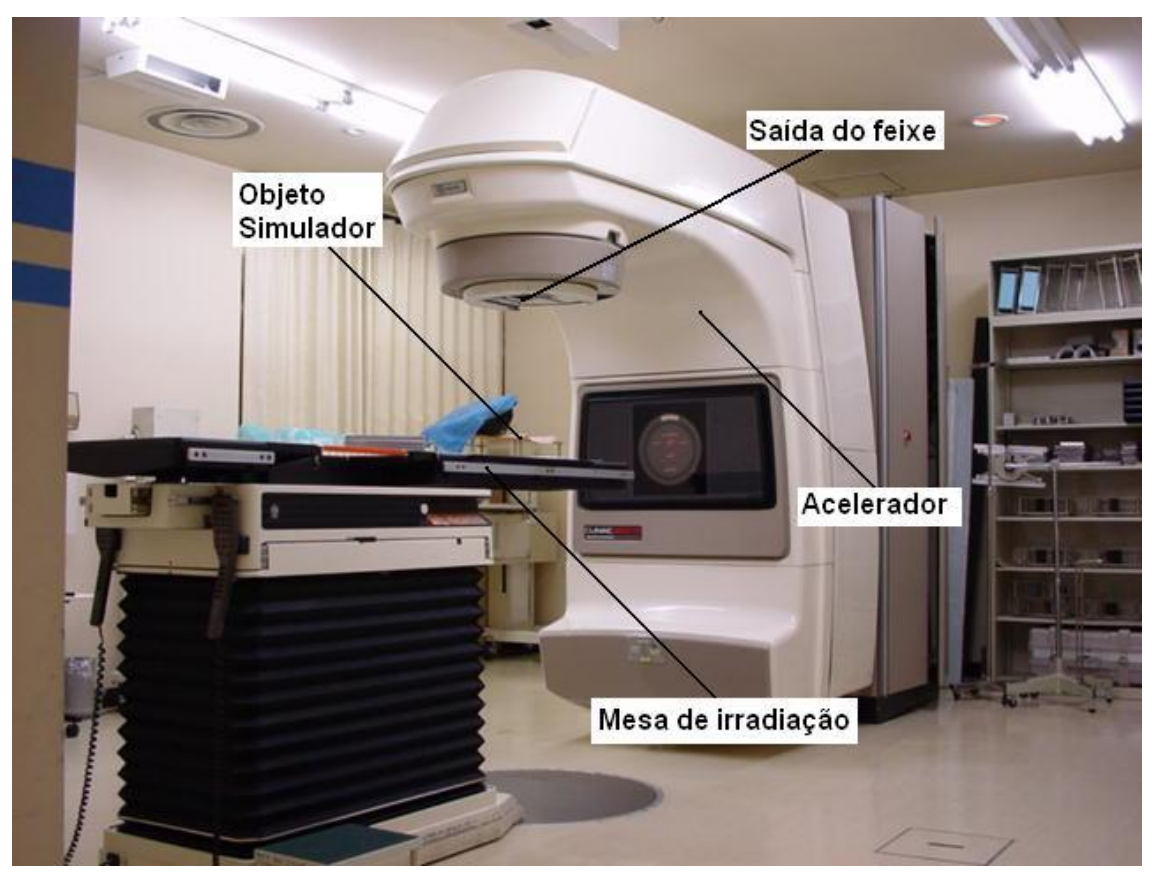

FIGURA 10: Sistema de irradiação no Acelerador Clinac 2100-C pertencente ao Hospital das Clínicas/USP.

\subsubsection{Reator de Pesquisa}

Para as medidas realizadas com amostras irradiadas com nêutrons térmicos foi utilizado o Beam Hole 3 (BH\#3) do reator de pesquisa do IEA-R1 do IPEN. O feixe do $B H \# 3$ é essencialmente constituído de radiação gama (com várias energias, já que o espectro é largo) e nêutrons (relativísticos, rápidos, epitérmicos e térmicos), com taxas de dose de 0,34 Gy/min para nêutrons e 0,085 $\mathrm{Gy} / \mathrm{min}$ para radiação gama. A taxa de dose varia até $1 \%$ em razão do liga/desliga do reator, o que ocorre semanalmente.

Os dosímetros foram fixados em diferentes posições e quantidades em um suporte de acrílico próprio desenvolvido especificamente para o $\mathrm{BH \# 3.} \mathrm{A} \mathrm{posição} \mathrm{de}$ irradiação do conjunto dosímetro/suporte pode ser observada na "posição da amostra" indicada na FIG.11. 


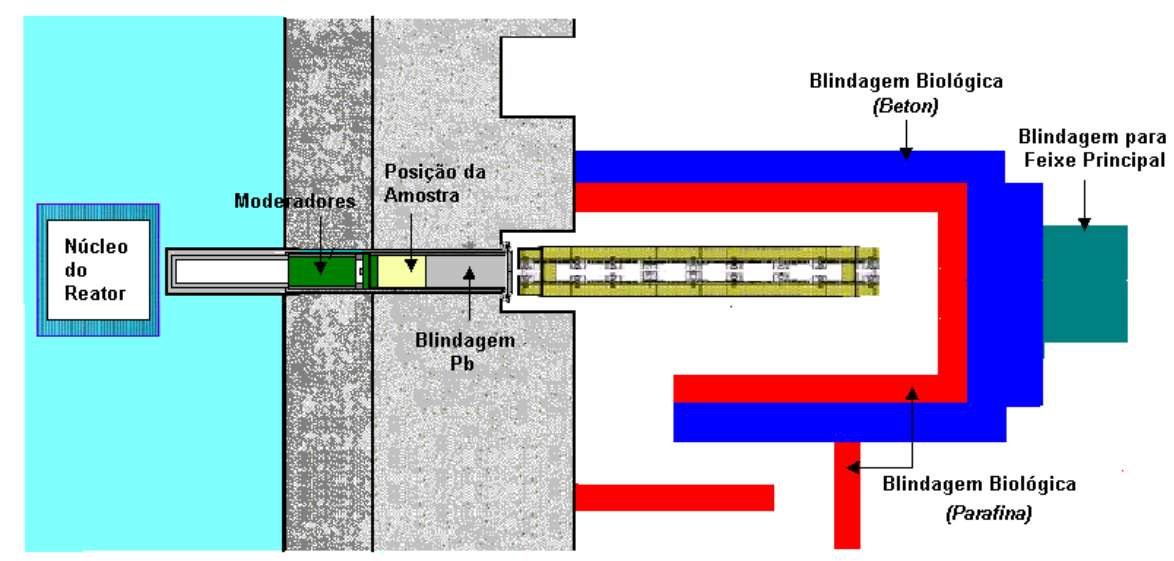

FIGURA 11: Esquema em corte horizontal do BH\#3 do reator de pesquisa IEA-R1 com o suporte na "posição da amostra".

\subsection{Leitura do sinal óptico}

A leitura da densidade óptica foi realizada em um espectrofotômetro Shimadzu UV-2101 PC, que pertence à Gerência de Metrologia das Radiações do IPEN, usando os parâmetros de medida apresentados na TAB.8:

TABELA 8: Parâmetros de medida do Espectrofôtometro Shimadzu UV-2101 PC.

\begin{tabular}{cc}
\hline Parâmetros & \\
\hline Intervalo de comprimento de onda & $400-700 \mathrm{~nm}$ \\
Fonte de Luz & Tungstênio e Deutério \\
Largura da fenda & $2 \mathrm{~nm}$ \\
Absorvância & $-9.999-+9.999 \%$ \\
Transmitância & $-999.9-+999.9 \%$ \\
Velocidade de Varredura & 1600 (fast e intervalo de 2nm) \\
Precisão & $0.1 \mathrm{~nm}$ \\
\hline
\end{tabular}

Para as medidas de absorvância foi escolhida a banda de $585 \mathrm{~nm}$, que corresponde aos íons Férricos, ao invés da banda de $457 \mathrm{~nm}$, que corresponde aos íons Ferrosos, pois a variação entre as respostas ópticas para diferentes doses são maiores na banda de $585 \mathrm{~nm}$. 
O tempo entre a irradiação das amostras e a leitura no espectrofotômetro sempre foi de $1 \mathrm{~h}$.

\subsection{Comportamento da solução gel de Alanina para diferentes tipos de radiações}

As propriedades dosimétricas foram estudadas para cada tipo de radiação, exceto a propriedade de estabilidade para doses altas de elétrons. Os fatores externos na dosimetria da radiação também foram estudados, dentre eles, dependência energética e com a taxa de dose da resposta.

\subsubsection{Tratamento dos Dados}

Os pontos apresentados nas curvas representam 0 valor médio de 4 amostras diferentes, com duas leituras de cada amostra, subtraído o valor médio da leitura das 4 amostras que não foram irradiadas. As barras de incerteza mostram o desvio-padrão do valor médio resultante.

\subsubsection{Radiação Gama}

As propriedades dosimétricas do gel de Alanina avaliadas com a irradiação com a radiação Gama de ${ }^{60} \mathrm{Co}$ foram:

- Tempo ideal de estocagem do gel antes da irradiação;

- Dose Resposta;

- Reprodutibilidade;

- Dependência com a taxa de dose;

- Estabilidade.

\subsubsection{Determinação do tempo de estocagem do gel pré-irradiação}

Este ensaio consiste em determinar em que intervalo de tempo se verifica a estabilidade da resposta óptica do gel em relação ao tempo de estocagem no refrigerador. Para isso, as amostras foram divididas em 19 grupos com 8 cubetas, cada grupo foi mantido no refrigerador em um tempo de estocagem diferente, que variou entre 0 e 54 horas. Metade das cubetas de cada grupo foi irradiada no 
irradiador tipo Gammacell com dose de $30 \mathrm{~Gy}$, sendo que a outra metade de cada grupo foi considerada como valor de referência. Os resultados foram apresentados no item 5.1.2.

\subsubsection{Dose resposta/Reprodutibilidade}

As amostras foram divididas em 16 grupos com 4 cubetas cada e irradiadas com diferentes doses entre 0,5 e 50 Gy, exceto um grupo que foi utilizado como valor de referência. Para as doses menores que 5 Gy foi usada a fonte Panorâmica, para as doses maiores ou iguais a 5 Gy foi utilizado a fonte Gammacell. Os resultados foram apresentados nos itens 5.1 .3 e 5.1.4.

\subsubsection{Dependência da resposta com a taxa de dose}

O estudo realizado foi composto por 24 cubetas, divididas em 6 grupos e irradiados com a mesma dose de 5 Gy no irradiador tipo Gammacell, mas com taxas de dose entre 21,8 e $250 \mathrm{~Gy} / \mathrm{h}$, exceto um grupo não foi irradiado considerado como valor de referência. Os resultados foram apresentados no item 5.1.5.

\subsubsection{Estabilidade}

Um conjunto de 8 amostras foi irradiado com dose de 5 Gy no irradiador tipo Gammacell, e foram feitas as leituras do sinal da resposta até $27^{\circ}$ dia após a irradiação. As amostras foram mantidas à temperatura de $5^{\circ} \mathrm{C}$ e ao abrigo de luz. Os resultados foram apresentados no item 5.1.6.

\subsubsection{Feixe Clínico de Fótons}

As propriedades dosimétricas do gel de Alanina avaliadas para a irradiação com feixes clínicos de fótons foram:

- Dose resposta;

- Reprodutibilidade;

- Dependência da resposta óptica com a energia e taxa de dose. 


\subsubsection{Dose Resposta/Reprodutibilidade}

As amostras foram divididas em 7 grupos com 5 cubetas cada e irradiadas com doses entre 1 e 40 Gy com energia de $6 \mathrm{MeV}$ e taxa de Dose de 320 cGy/min, exceto um grupo que foi utilizado como valor de referência. Os resultados foram apresentados nos itens 5.2 .2 e 5.2.3.

\subsubsection{Dependência Energética}

Três grupos, com 5 amostras cada, foram irradiados com dose de 5 Gy e com fótons com energias de 6 e $15 \mathrm{MeV}$ com taxa de dose de $320 \mathrm{cGy} / \mathrm{min}$, exceto um grupo não foi irradiado considerado como valor de referência. Foi realizado o mesmo teste para dose de 30 Gy. Os resultados foram apresentados no item 5.2.4.

\subsubsection{Dependência da resposta com a taxa de dose}

O estudo realizado foi composto por 24 cubetas, divididas em 6 grupos, irradiados com a mesma dose de 5 Gy e energia de $6 \mathrm{MeV}$, mas com taxas de dose entre 120 e $360 \mathrm{~Gy} / \mathrm{h}$, exceto um grupo não foi irradiado considerado como valor de referência. $O$ mesmo estudo foi realizado com dose de 30 Gy. Os resultados foram apresentados no item 5.2.5.

\subsubsection{Feixe Clínico de Elétrons}

As propriedades dosimétricas do gel de Alanina avaliadas para a irradiação com Elétrons de nível radioterápico foram:

- Dose Resposta;

- Reprodutibilidade;

- Dependência da resposta óptica com a energia e taxa de dose;

- Estabilidade.

\subsubsection{Dose Resposta/Reprodutibilidade}

As amostras foram divididas em 7 grupos com 5 cubetas cada e irradiadas com doses entre 1 e 40 Gy com energia de $6 \mathrm{MeV}$ e taxa de dose de $320 \mathrm{cGy} / \mathrm{min}$, 
exceto um grupo não foi irradiado, pois foi utilizado como valor de referência. Os resultados foram apresentados nos itens 5.3 .2 e 5.3.3.

\subsubsection{Dependência Energética}

Quatro grupos, com 5 amostras cada, foram irradiados com dose de 5 Gy e taxa de dose de 320 cGy com elétrons com energias de 6, 9 e $15 \mathrm{MeV}$, exceto um grupo não foi irradiado considerado como valor de referência. Foi realizado o mesmo teste para dose de $30 \mathrm{~Gy}$. Os resultados foram apresentados no item 5.3.4.

\subsubsection{Dependência da resposta com a taxa de dose}

O estudo realizado foi composto por 24 cubetas, divididas em 6 grupos e irradiados com a mesma dose de $5 \mathrm{~Gy}$ e com elétrons com energia de $6 \mathrm{MeV}$, mas com taxas de dose entre 120 e $360 \mathrm{~Gy} / \mathrm{h}$, exceto um grupo não foi irradiado considerado como valor de referência. O mesmo estudo foi realizado com dose de 30 Gy. Os resultados foram apresentados no item 5.3.5.

\subsubsection{Estabilidade}

Um conjunto de 30 amostras, divididas em 2 grupos foram irradiadas com doses de 5 e $30 \mathrm{~Gy}$, com elétrons com energia de $6 \mathrm{MeV}$ e com taxa de dose de $320 \mathrm{cGy} / \mathrm{min}$, e foram realizadas medidas da leitura do sinal da resposta até o $3^{\circ}$ dia após a irradiação. As amostras foram mantidas à temperatura de $5^{\circ} \mathrm{C}$ e ao abrigo de luz. Os resultados foram apresentados no item 5.3.6.

\subsubsection{Elétrons Aplicações Industriais}

As propriedades dosimétricas do gel de Alanina avaliadas para a irradiação com Elétrons com doses altas e energia de aproximadamente 1,5 MeV:

- Dose Resposta;

- Reprodutibilidade. 


\subsubsection{Dose Resposta/Reprodutibilidade}

O estudo foi composto por lotes constituídos por 20 cubetas de cada solução, dividida em 5 grupos. Cada grupo foi irradiado com diferentes doses entre 0,5 kGy e $10 \mathrm{kGy}$, com energia de $6 \mathrm{MeV}$ e taxa de dose de $320 \mathrm{cGy} / \mathrm{min}$, exceto um grupo não foi irradiado, utilizado como valor de referência. Os resultados foram apresentados nos itens 5.5.2 e 5.5.3.

\subsubsection{Nêutrons Térmicos do Reator de Pesquisa}

As propriedades dosimétricas do gel de Alanina avaliadas com a irradiação para Nêutrons do reator foram:

- Dose Resposta;

- Reprodutibilidade;

- Determinação da razão Gama/Nêutrons no feixe do reator de pesquisa IEA-R1.

\subsubsection{Dose Resposta/Reprodutibilidade}

Os dosímetros, com bórax adicionado, foram divididos em 7 grupos com 3 cubetas cada e irradiados no $\mathrm{BH} 3$ do reator de pesquisa do IEA-R1 com doses entre 4,25 e 51 Gy, exceto um grupo que foi considerado como valor de referência. As doses absorvidas de nêutrons e radiação gama foram determinadas usando dosímetros de LiF Albedo pelo grupo de pesquisa do Centro de Engenharia Nuclear (CEN). As cubetas foram posicionadas de modo que o centro óptico esteja de acordo com o centro geométrico do feixe, e o eixo longitudinal da cubeta é perpendicular ao centro geométrico do feixe. Os resultados foram apresentados nos itens 5.6 .2 e 5.6.3.

\subsubsection{Avaliação da dose gama/nêutrons no Reator de Pesquisa}

Paralelamente ao experimento de reprodutibilidade e dose resposta, outro conjunto de dosímetros, com bórax adicionado, foi dividido em 8 grupos com 3 cubetas cada, e as cubetas irradiadas com radiação gama do ${ }^{60} \mathrm{Co}$ (GammaCell) com doses entre 0,85 e 15 Gy para obtenção das curvas de dose resposta para a solução 
Alanina gel com e sem adição de ${ }^{10} \mathrm{~B}$. Os resultados foram apresentados no item 5.6.4.

\subsubsection{Limite mínimo de Detecção}

O limite mínimo de detecção (LID) foi calculado para os feixes de fótons e elétrons, e consiste em medidas realizadas sobre um número grande de dosímetros não-irradiados (Boas, 1966), 30 amostras, e é dado pela EQ.7. Os resultados foram apresentados no item 5.7 . 


\section{$5 \quad$ RESULTADOS E DISCUSSÕES}

\subsection{Radiação Gama do ${ }^{60} \mathrm{Co}$}

\subsubsection{Espectro típico da solução gel de Alanina para radiação gama do ${ }^{60} \mathrm{Co}$}

$\mathrm{O}$ espectro típico da solução gel de Alanina para radiação gama do ${ }^{60} \mathrm{Co}$ é mostrado na FIG.12:

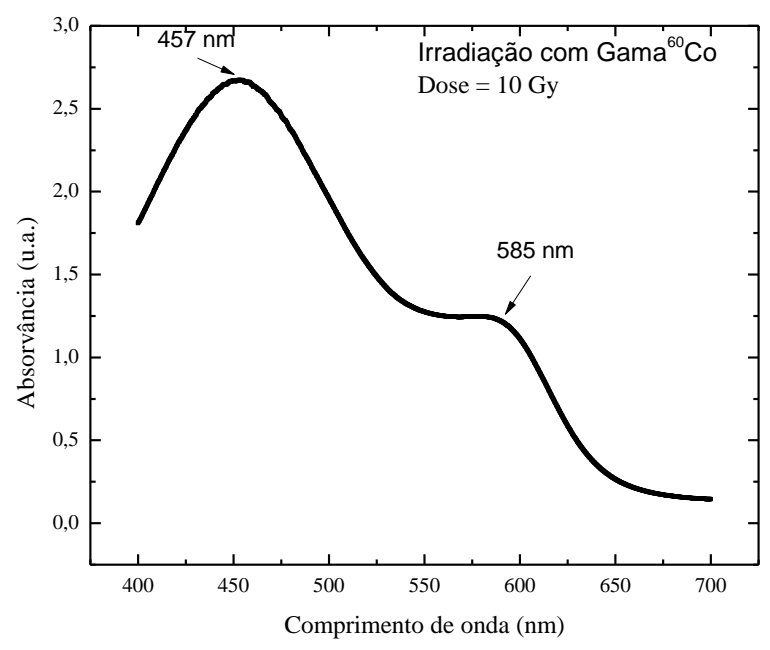

FIGURA 12: Espectro típico da solução gel de Alanina para radiação gama de ${ }^{60} \mathrm{Co}$.

A banda de $457 \mathrm{~nm}$ corresponde à presença dos íons de $\mathrm{Fe}^{2+}$, enquanto que a banda de $585 \mathrm{~nm}$ corresponde à presença dos íons de $\mathrm{Fe}^{3+}$.

\subsubsection{Determinação do tempo ótimo de estocagem do gel para irradiação}

Como pode ser observada nas FIG.13 e FIG.14, a dependência da resposta óptica em relação ao tempo de estocagem no refrigerador a $5^{\circ} \mathrm{C}$ entre $20 \mathrm{e}$ $54 \mathrm{~h}$ é melhor que $1,2 \%$, o que indica que pode ser considerado a resposta óptica independe do tempo de estocagem neste intervalo, onde há uma região de estabilidade da resposta do gel dosimétrico. 


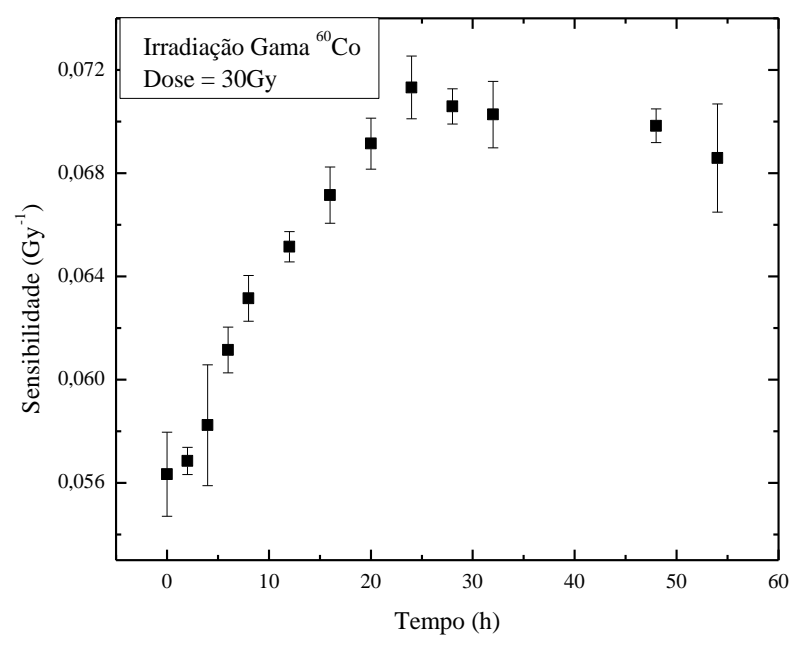

FIGURA 13: Resposta óptica da solução gel de Alanina para o período de estocagem pré-irradiação.

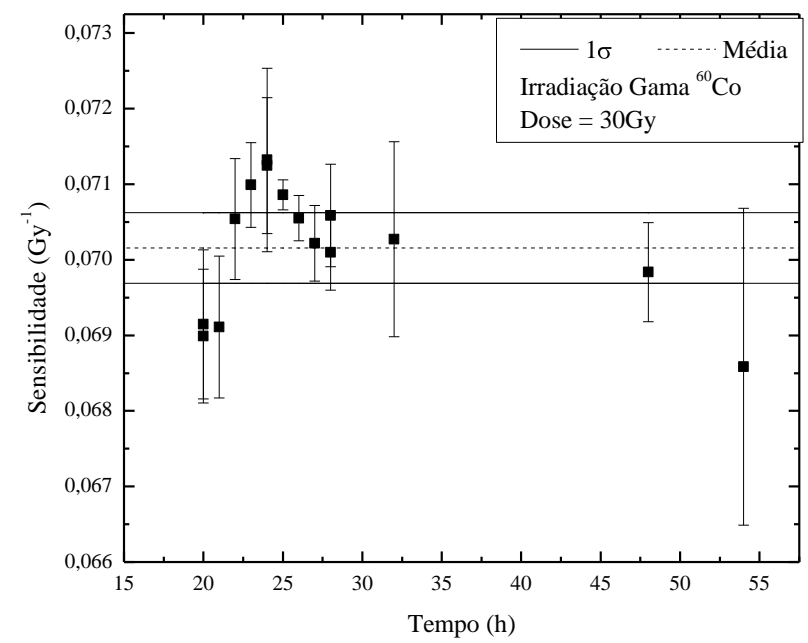

FIGURA 14: Resposta óptica da solução gel de Alanina entre 20 e 54 h de estocagem pré-irradiação.

\subsubsection{Dose Resposta}

A solução gel de Alanina apresenta comportamento linear da resposta para doses de radiação gama entre 0,5 e 50 Gy conforme a FIG. 15 . 


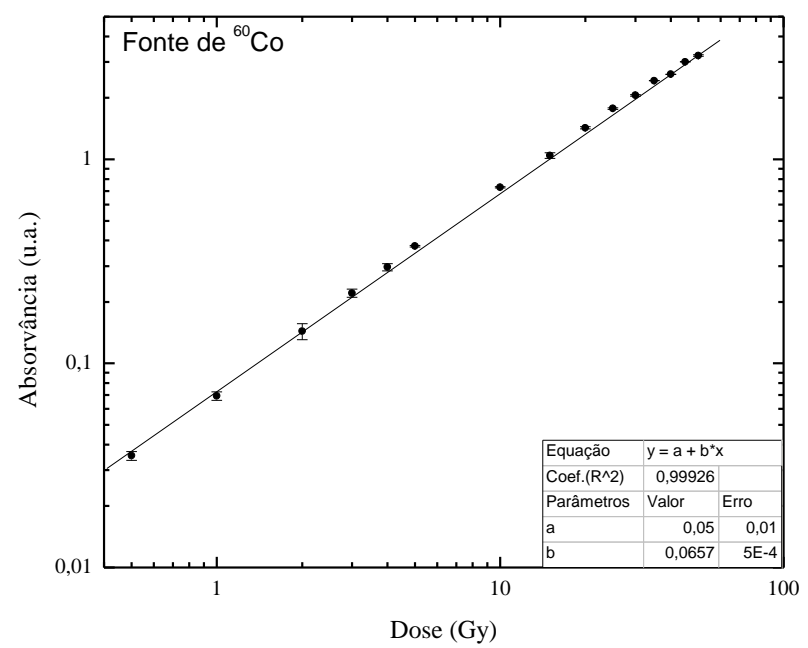

FIGURA 15: Curva de dose resposta da solução gel de Alanina para radiação gama.

\subsubsection{Reprodutibilidade}

A reprodutibilidade intra-lote foi avaliada tornando o desvio padrão (1б) de 6 amostras diferentes de um mesmo lote, irradiadas com doses entre 0,5 e 50 Gy no irradiador Gamacell. A resposta óptica apresenta desvio-padrão melhor que 4\%.

A reprodutibilidade inter-lotes da resposta da solução Alanina gel foi

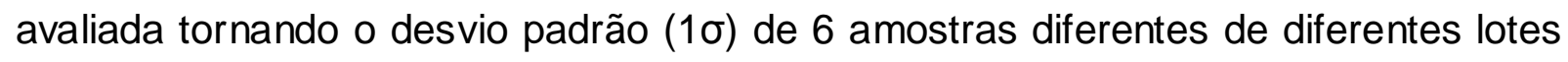
e irradiadas com doses entre 0,5 e 50 Gy, a resposta óptica apresenta desvio-padrão melhor que 4\%, que é mostrado na FIG.16. 


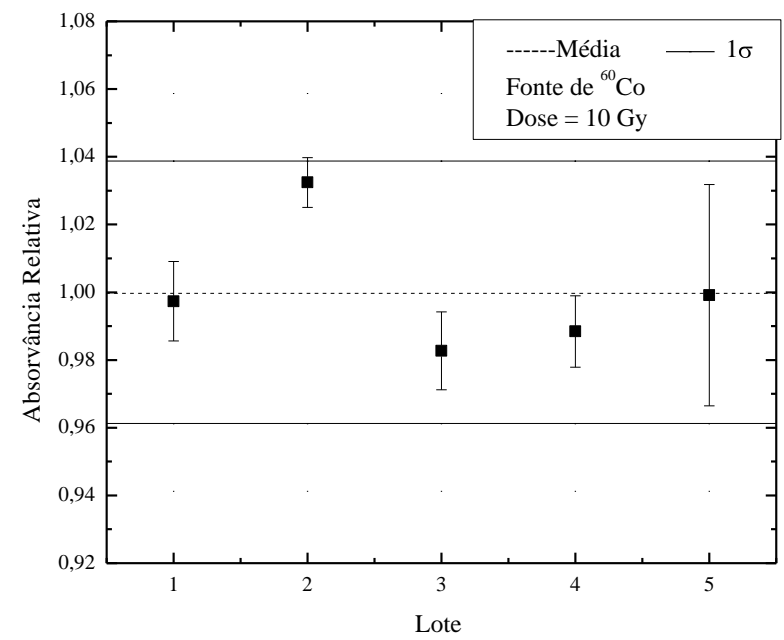

FIGURA 16: Reprodutibilidade inter-lotes da solução gel de Alanina para radiação gama.

\subsubsection{Dependência da resposta com a Taxa de dose}

De acordo com os resultados apresentados na FIG.17, a dependência da resposta com a de taxa de dose para a solução de gel de Alanina é melhor que 1,8\% $(1 \sigma)$, o que indica que podemos considerar a resposta óptica independente da taxa de dose no intervalo entre 21,8 e $250 \mathrm{~Gy} / \mathrm{h}$ estudado.

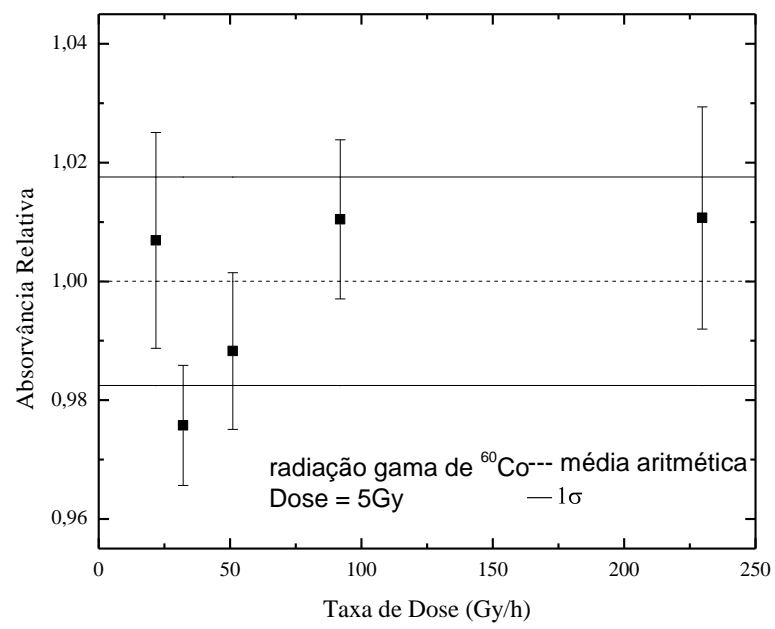

FIGURA 17: Dependência da resposta da solução gel de Alanina em função da taxa de dose. 


\subsubsection{Estabilidade}

A resposta óptica é estável entre 1 a $2 \mathrm{~h}$ depois da irradiação. Depois deste tempo, apresenta um comportamento linear crescente até o $8^{\circ}$ dia e sublinear até 0 25으 dia, em que apresenta saturação da resposta óptica, conforme os dados apresentados na FIG.18 e FIG.19. O dia zero é considerado duas horas após a irradiação.

Esse resultado pode ser explicado pela oxidação natural dos íons de $\mathrm{Fe}^{2+}$ com o passar do tempo, nas condições em que foi avaliado.

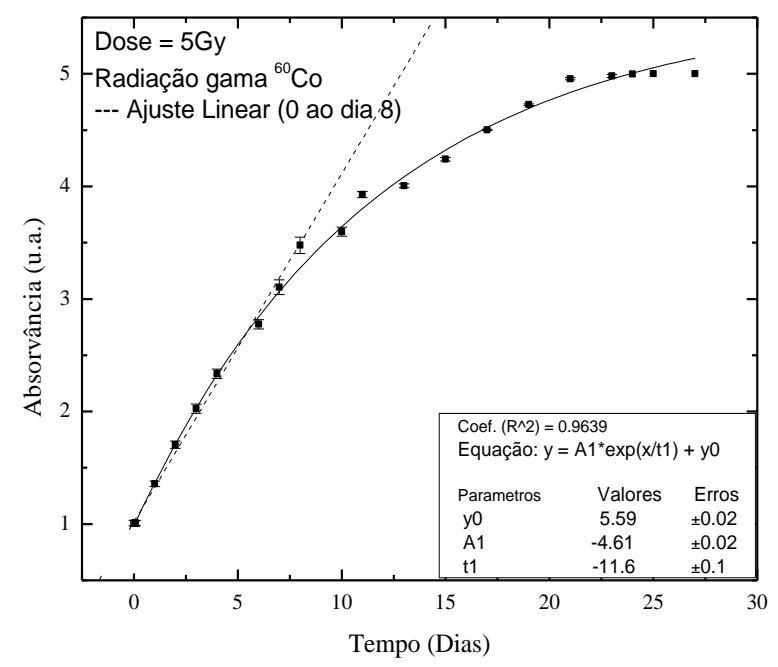

FIGURA 18: Resposta da solução gel de Alanina como uma função do tempo de estocagem após a irradiação. 


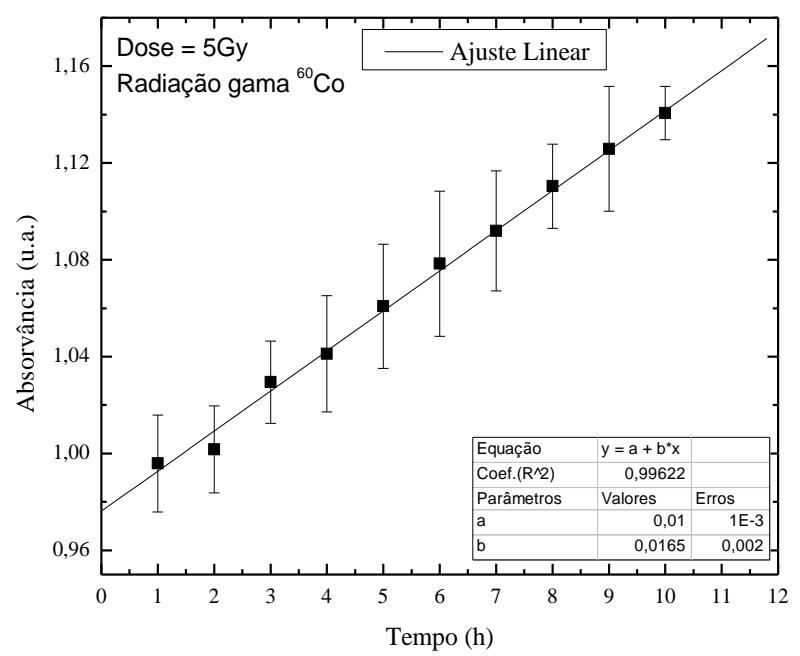

FIGURA 19: Resposta da solução gel de Alanina como uma função do tempo de estocagem após a irradiação.

\subsection{Feixe Clínico de Fótons}

\subsubsection{Espectro típico da solução gel de Alanina para radiação de Feixe Clínico de Fótons}

O espectro típico da solução gel de Alanina para radiação de fótons clínicos é mostrada na FIG.20:

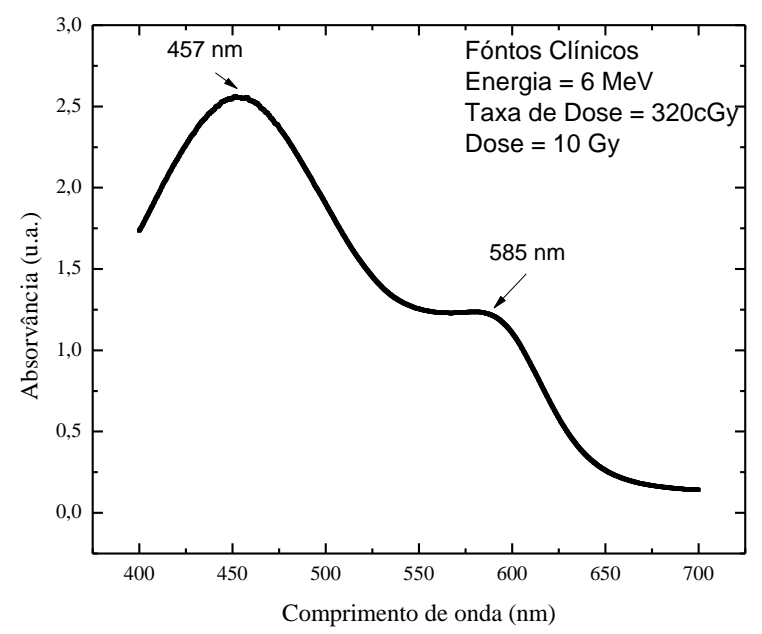

FIGURA 20: Espectro típico da solução gel de Alanina para radiação de feixe clínico de fótons. 
As mesmas bandas presentes no espectro da solução gel de Alanina para radiação de ${ }^{60} \mathrm{Co}$ são observadas para radiação com fótons clínicos.

\subsubsection{Dose Resposta}

A solução gel de Alanina apresenta comportamento linear da resposta para fótons de $6 \mathrm{MeV}$ para doses entre 1 e 40 Gy, conforme a FIG.21.

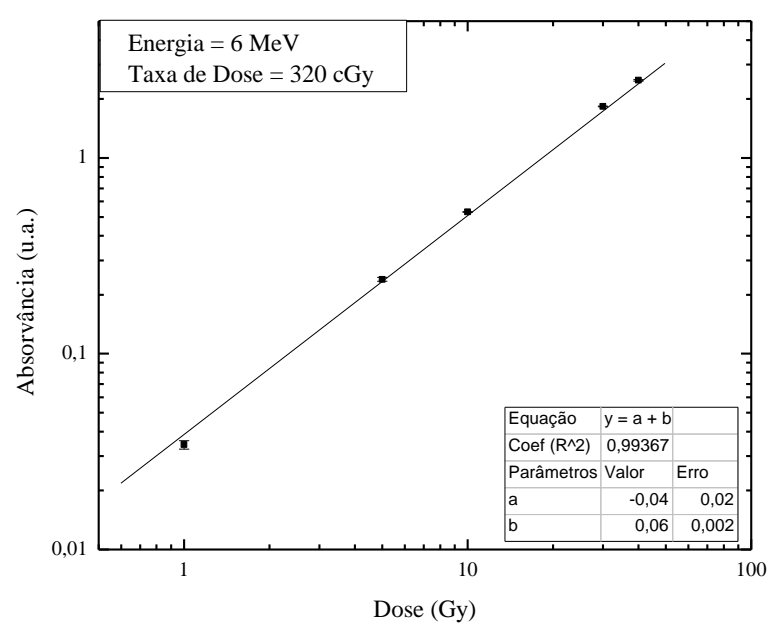

FIGURA 21: Curva de dose resposta da solução gel de Alanina para fótons de $6 \mathrm{MeV}$.

\subsubsection{Reprodutibilidade}

A reprodutibilidade intra-lote para fótons clínicos de $6 \mathrm{MeV}$ foi avaliada tornando o desvio padrão ( $1 \sigma)$ da média da resposta de 5 amostras diferentes em um mesmo lote, irradiadas com doses entre 1 e 40 Gy. A resposta óptica apresenta desvio-padrão melhor que $4 \%$.

A reprodutibilidade inter-lotes da resposta da solução gel de Alanina para fótons de energia de $6 \mathrm{MeV}$ foi avaliada tornando o desvio padrão $(1 \sigma)$ da média da resposta de 5 amostras diferentes em diferentes lotes e irradiadas com doses entre 1 e 40 Gy. A resposta óptica apresenta desvio-padrão melhor que 4\%, como pode ser observado na FIG.22. 


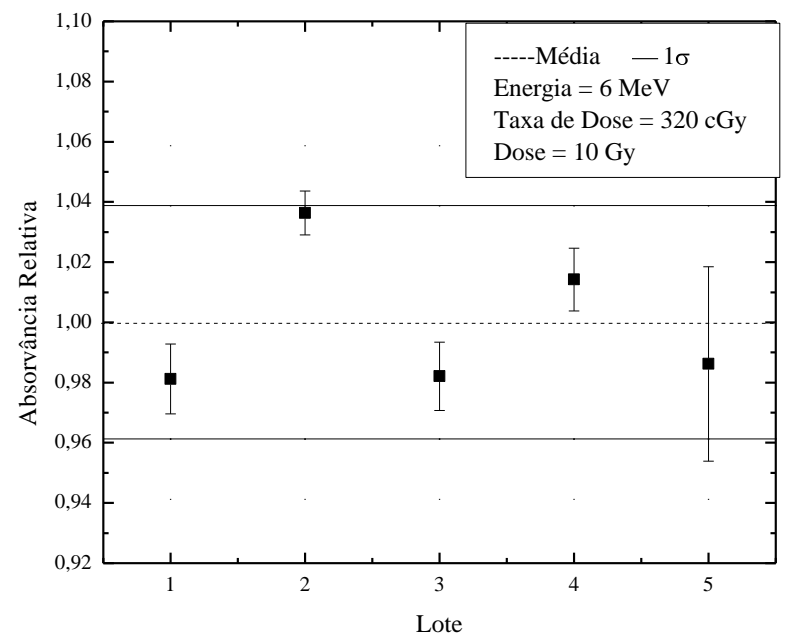

FIGURA 22: Reprodutibilidade inter-lotes da resposta da solução de gel de Alanina para radiação de fótons de $6 \mathrm{MeV}$.

\subsubsection{Dependência Energética da Resposta}

De acordo com a FIG.23, a dependência energética relativa à radiação

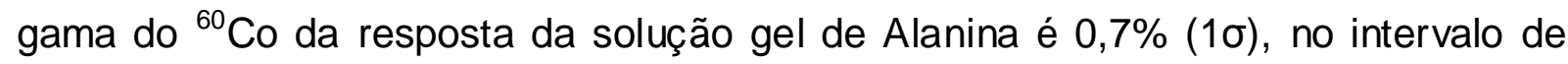
energias estudadas, o que indica que podemos considerar a resposta óptica independente para energia.

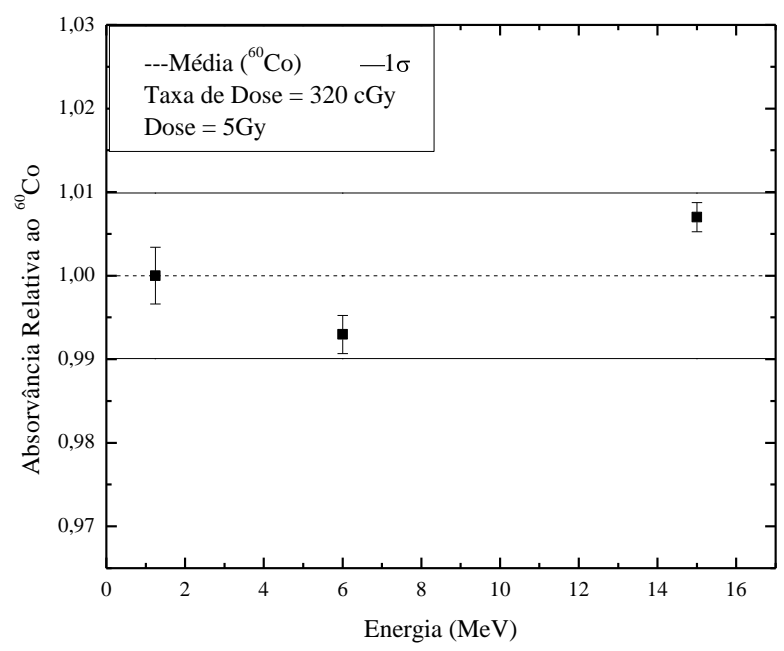

FIGURA 23: Dependência Energética relativa à radiação gama do ${ }^{60} \mathrm{Co}$ da resposta da solução gel de Alanina para feixe clínico de fótons. 


\subsubsection{Dependência da Resposta com a Taxa de dose}

De acordo com a FIG.24, a dependência da resposta da solução gel de Alanina em função da taxa de dose para radiação de fótons clínicos é melhor que $1,9 \%(1 \sigma)$ no intervalo de taxas de dose estudado, o que indica que podemos considerar a resposta óptica independente da taxa de dose.

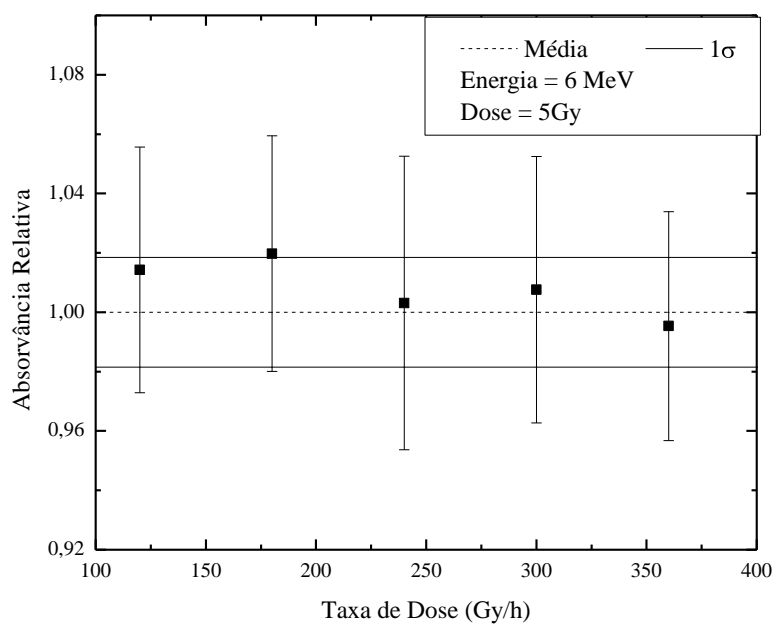

FIGURA 24: Dependência da resposta da solução gel de Alanina em função da taxa de dose para dose de 5 Gy.

\subsubsection{Estabilidade}

Como os espectros e as curvas de dose-resposta são semelhantes tanto para radiação gama quanto para fótons clínicos, e também, como não há dependência energética da resposta, foi considerado que a estabilidade do sinal é a mesma para ambos os tipos de radiação, ou seja, o aumento do sinal óptico deve ser o mesmo apresentado na FIG.15. Isso é válido para as amostras mantidas a temperatura de $5^{\circ} \mathrm{C}$ e ao abrigo de luz.

\subsection{Feixe Clínico de Elétrons}

\subsubsection{Espectro típico da solução gel de Alanina para Feixe Clínico de Elétrons}

O espectro típico da solução gel de Alanina para radiação de elétrons clínicos é mostrada na FIG.25: 


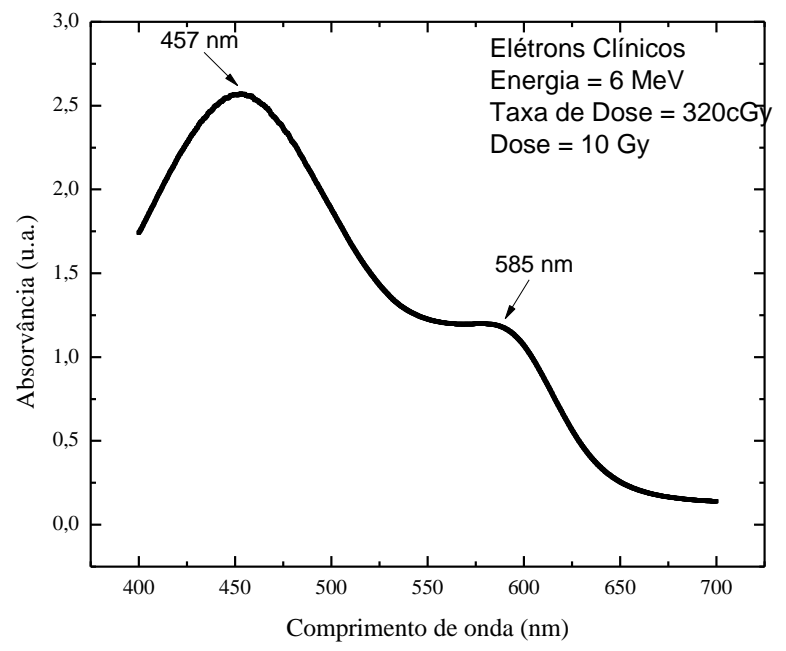

FIGURA 25: Espectro típico da solução gel de Alanina para radiação de feixe clínico de elétrons.

Não foi observada qualquer alteração no espectro em relação à resposta para radiação gama de ${ }^{60} \mathrm{Co}$. As mesmas bandas, com os mesmos comprimentos de onda, presentes nos espectros da solução de Alanina para radiação de ${ }^{60} \mathrm{Co}$ e fótons clínicos são observadas para radiação com elétrons clínicos.

\subsubsection{Dose Resposta}

A solução gel de Alanina apresenta comportamento linear da resposta para doses de elétrons entre 1 e 40 Gy conforme a FIG.26. 


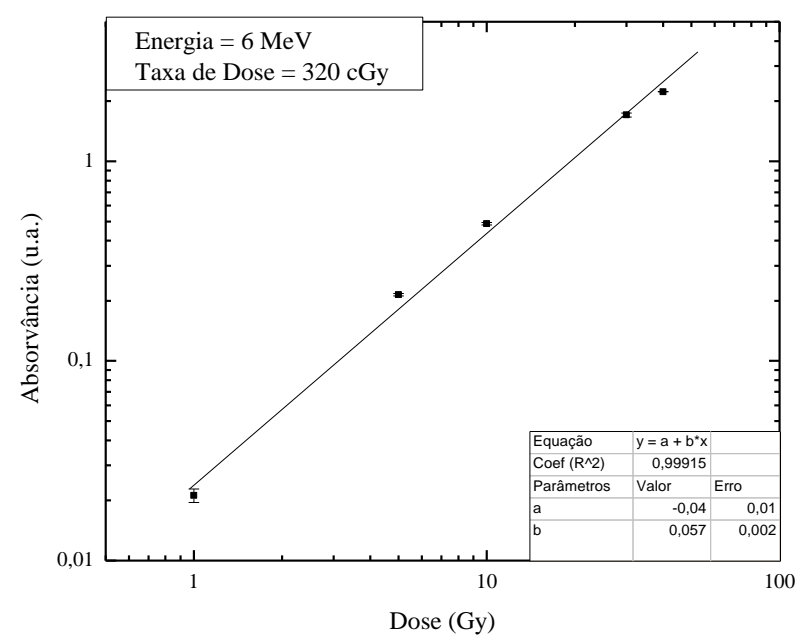

FIGURA 26: Curva de dose resposta da solução gel de Alanina para feixe clínico de elétrons.

\subsubsection{Reprodutibilidade}

A reprodutibilidade intra-lote foi avaliada tornando o desvio padrão (1б) da média da resposta de 5 amostras diferentes em um mesmo lote, irradiadas com doses entre 1 e 40 Gy com elétrons de energia de $6 \mathrm{MeV}$, a resposta óptica apresenta desvio-padrão de $4 \%$.

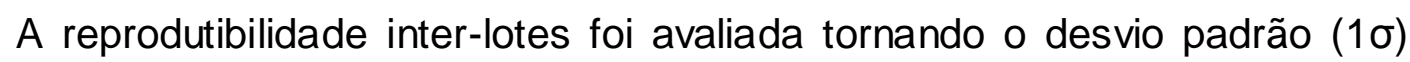
da média da resposta de 5 amostras diferentes de diferentes lotes e irradiadas com doses entre 1 e $40 \mathrm{~Gy}$ com elétrons de energia de $6 \mathrm{MeV}$, a resposta óptica apresenta desvio-padrão de 5\%, como pode ser observado na FIG.27. 


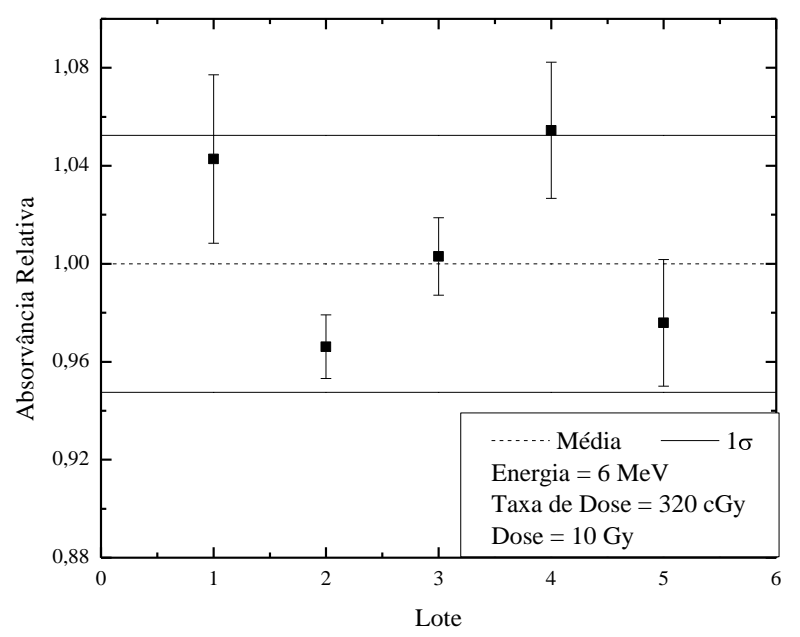

FIGURA 27: Reprodutibilidade inter-lotes da resposta da solução gel de Alanina para feixe clínico de elétrons.

\subsubsection{Dependência Energética}

De acordo com a FIG.28, a dependência energética da resposta da solução gel de Alanina é $3 \%(1 \sigma)$, o que indica que podemos considerar a resposta óptica independente da energia no intervalo de energias estudado.

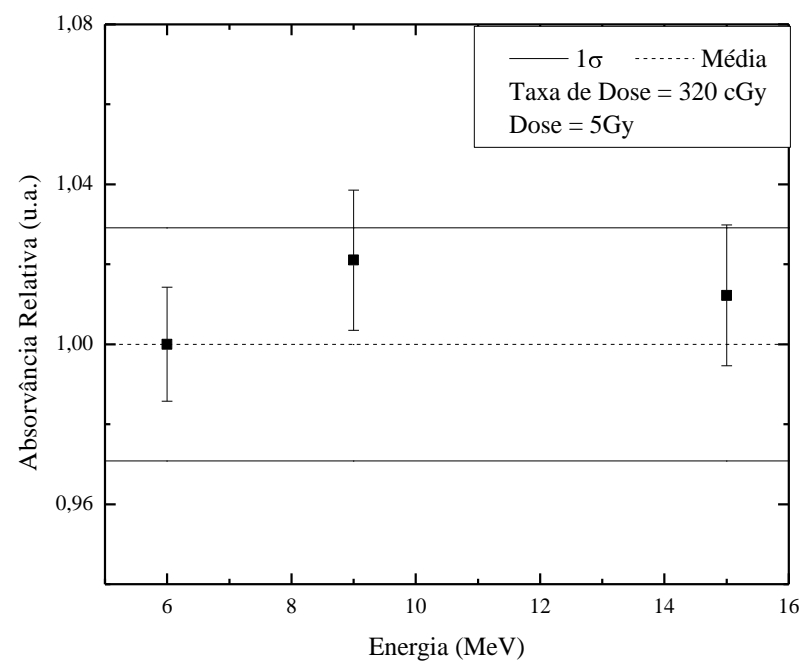

FIGURA 28: Dependência energética relativa da resposta da solução gel de Alanina para feixe clínico de elétrons. 


\subsubsection{Dependência da Resposta com a Taxa de dose}

De acordo com a FIG.29, a dependência da resposta da resposta da solução gel de Alanina em função da taxa de é melhor que $2 \%(1 \sigma)$, o que indica que podemos considerar a resposta óptica independente com a taxa de dose no intervalo de taxas entre 120 e $360 \mathrm{~Gy} / \mathrm{h}$.

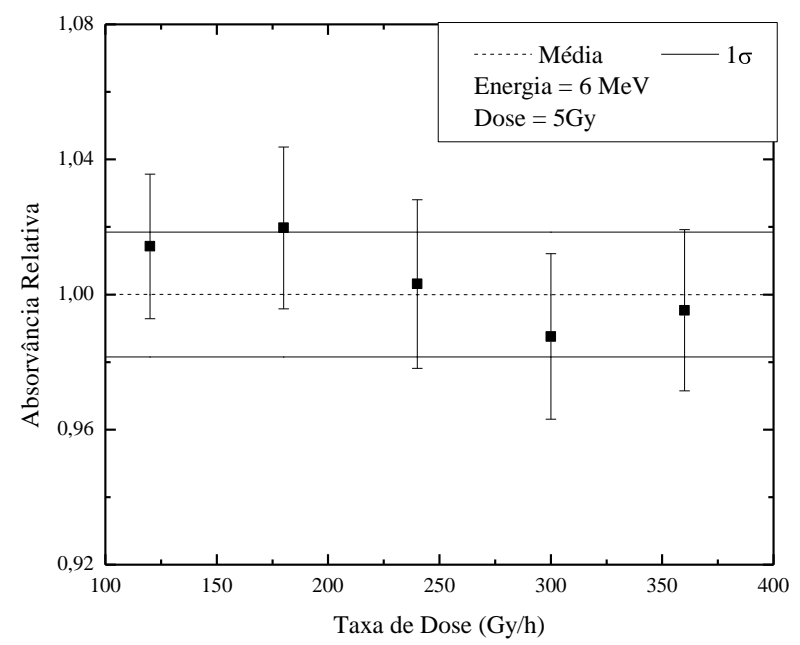

FIGURA 29: Dependência da resposta da solução gel de Alanina em função da taxa de dose para feixe clínico de elétrons.

\subsubsection{Estabilidade}

De acordo com a FIG.30, a resposta óptica da solução gel de Alanina em relação ao tempo decorrido após irradiação é linear e crescente entre o dia 0 e 3 de acordo com a condição descrita em 4.4.4.4. O dia 0 foi considerado o tempo em que a resposta óptica não varia, que neste caso é de duas horas. 


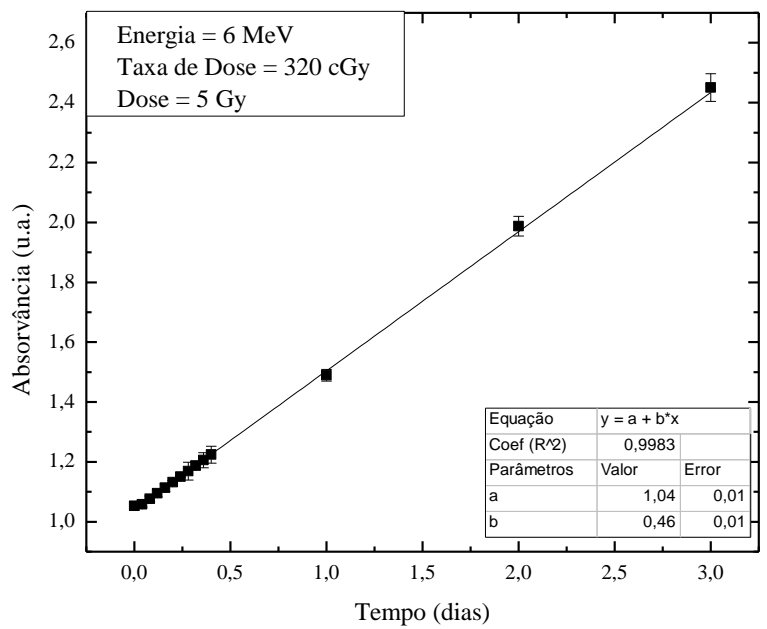

FIGURA 30: Resposta da solução gel de Alanina em função do tempo de estocagem após a irradiação.

Na FIG.31 é mostrada a resposta óptica em relação ao tempo decorrido nas primeiras horas depois da irradiação.

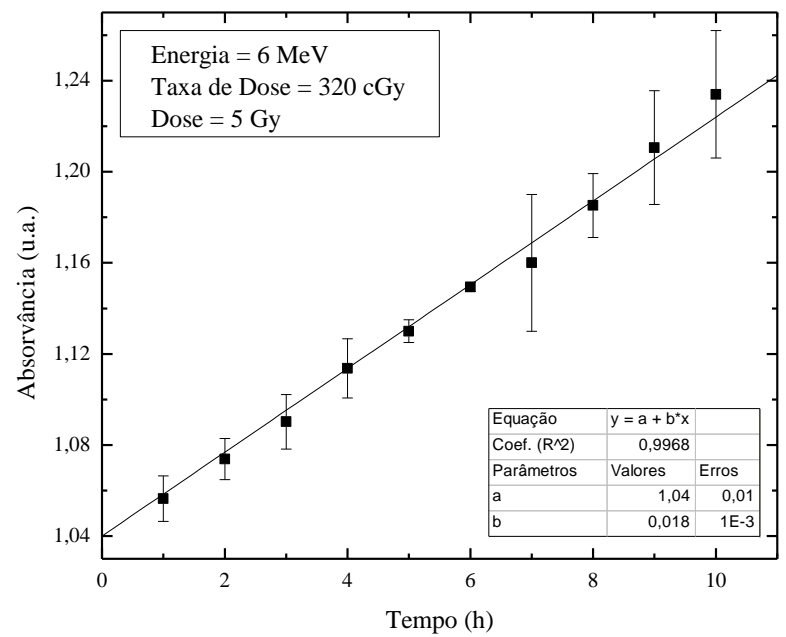

FIGURA 31: Resposta da solução gel de Alanina em função do tempo de estocagem após a irradiação.

Este resultado pode ser considerado semelhante ao observado para irradiação com radiação gama de ${ }^{60} \mathrm{Co}$. 
5.4 Comparação das curvas de dose resposta da solução gel de Alanina para radiação de ${ }^{60} \mathrm{Co}$ e Feixes Clínicos de Fótons e Elétrons

Na TAB.9 é apresentada a comparação da sensibilidade da solução Alanina gel para radiação do ${ }^{60} \mathrm{Co}$, fótons e elétrons clínicos de $6 \mathrm{MeV}$.

TABELA 9: Sensibilidade da solução gel de Alanina em função de diferentes tipos de radiação.

\begin{tabular}{cc}
\hline Tipo de radiação & Sensibilidade $\left(\mathrm{Gy}^{-1}\right)$ \\
\hline${ }^{60} \mathrm{Co}(\mathrm{E}=1,25 \mathrm{MeV})$ & $0,062 \pm 0,004$ \\
Fótons Clínicos $(\mathrm{E}=6 \mathrm{MeV})$ & $0,060 \pm 0,002$ \\
Elétrons clínicos $(\mathrm{E}=6 \mathrm{MeV})$ & $0,057 \pm 0,002$ \\
\hline
\end{tabular}

A sensibilidade da solução gel de Alanina para diferentes tipos de radiação é melhor que $4,2 \%$, o que indica que podemos considerar que a sensibilidade é independente para os diferentes tipos de radiação, para as energias estudadas.

\subsection{Elétrons (Aplicações Industriais)}

\subsubsection{Espectro típico da solução gel de Alanina para Elétrons (Aplicações Industriais) \\ O espectro típico da solução gel de Alanina para irradiação com elétrons para aplicações industriais, é mostrado na FIG.32:}




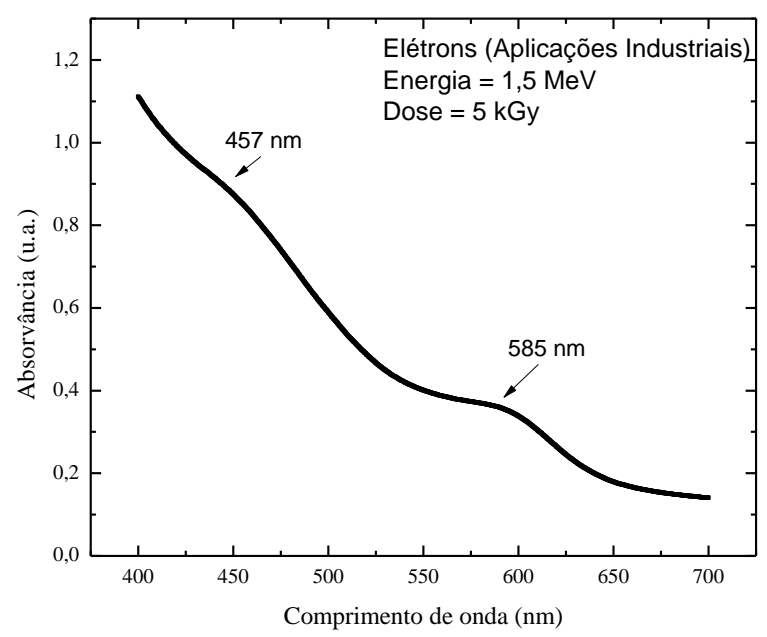

FIGURA 32: Espectro típico da solução gel de Alanina para elétrons (aplicações industriais).

Embora as mesmas bandas presente nos espectros da solução gel de Alanina para radiações estudadas anteriores sejam observadas para elétrons de aplicações industriais, pode ser observado na FIG.32 que as intensidades das mesmas não obedecem às intensidades de outras radiações.

\subsubsection{Dose Resposta}

Observa-se na FIG.33 que o comportamento da resposta óptica em função da dose é não-linear e decrescente, o que não era esperado, provavelmente, isso se deve, de acordo com lliev et al (2004), à destruição do Xilenol por radicais gerados na radiolise da água, portanto inviabilizando o uso deste dosímetro para aplicação com a radiação com elétrons de doses altas (aplicação industriais).

A hipótese da destruição do Xilenol presente na solução para a indicação dos íons ferrosos pode explicar a não definição das bandas de $457 \mathrm{~nm}$ e $585 \mathrm{~nm}$. 


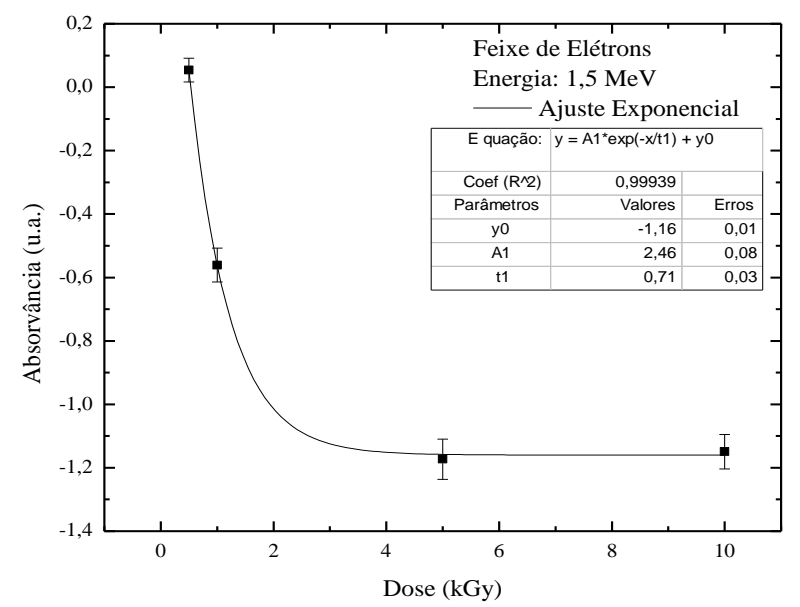

FIGURA 33: Curva de resposta da solução gel de Alanina em função da dose.

\subsubsection{Reprodutibilidade}

A reprodutibilidade da resposta da solução gel de Alanina intra-lote foi avaliada tornando o desvio padrão $(1 \sigma)$ da média de 3 amostras diferentes em um mesmo lote, irradiadas doses entre 0,5 e $10 \mathrm{kGy}$ com elétrons de energia de aproximadamente de 1,5 MeV. A resposta óptica apresenta desvio-padrão de 27\%, pois para a dose de 0,5 kGy, observa-se a formação de muitas bolhas de ar, provavelmente devido às doses altas, apresentando um desvio-padrão relativamente grande.

Essa diferença pode ser explicada pelo fato da dose ser excessivamente alta, há uma total extinção dos íons ferrosos e não detecção dos íons férricos induzidos pela radiação.

\subsection{Nêutrons Térmicos}

\subsubsection{Espectro típico da solução gel de Alanina para nêutrons}

O espectro típico da solução gel de Alanina com e sem ${ }^{10} \mathrm{~B}$ para radiação em campo misto gama/nêutrons é mostrada na FIG.34: 


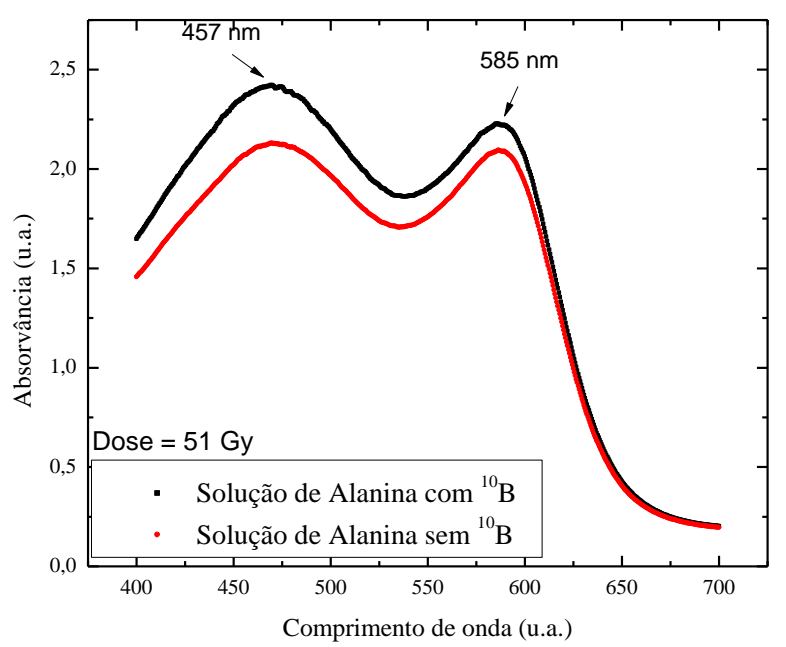

FIGURA 34: Espectro típico da solução gel de Alanina para campos mistos gama/nêutrons.

As mesmas bandas, com os mesmos comprimentos de onda, presentes nos espectros da solução gel de Alanina para radiações estudadas anteriormente são observadas para radiação em campo misto gama/nêutrons. Observa-se que a resposta óptica da solução gel de Alanina $\operatorname{com}^{10} \mathrm{~B}$ é mais intensa que a resposta óptica para a solução gel de Alanina sem ${ }^{10} \mathrm{~B}$, devido à contribuição da dose referente aos nêutrons como conseqüência da interação com o ${ }^{10} \mathrm{~B}$.

\subsubsection{Dose Resposta}

A solução gel de Alanina com ${ }^{10} \mathrm{~B}$ apresenta comportamento linear da resposta em campo misto gama/nêutron em função da dose gama/nêutrons entre 4,25 e 51 Gy, de acordo com a FIG.35. 


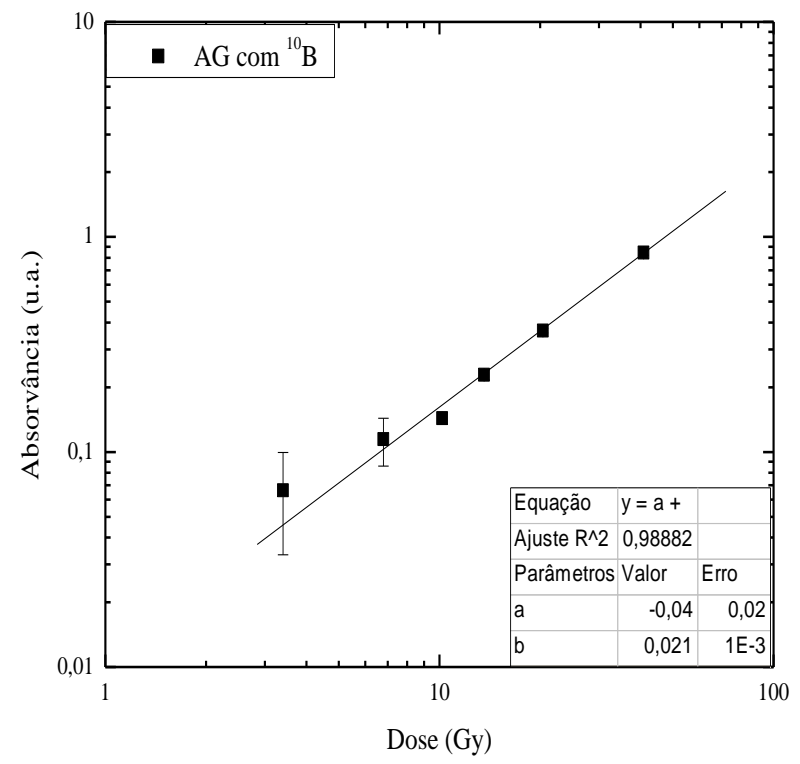

FIGURA 35: Curva de dose resposta da solução gel de Alanina com ${ }^{10} \mathrm{~B}$ para campos mistos gama/nêutron.

\subsubsection{Reprodutibilidade}

A reprodutibilidade intra-lote para a solução Alanina gel com ${ }^{10} \mathrm{~B}$ adicionado foi avaliada tornando o desvio padrão $(1 \sigma)$ da média de 5 amostras diferentes em um mesmo lote, irradiadas com radiação gama/nêutron com doses entre 4,25 e 51 Gy. A resposta óptica apresenta desvio-padrão de 5\%.

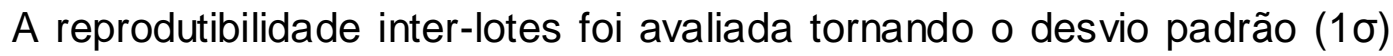
da média de 5 amostras diferentes em diferentes lotes e irradiadas com doses entre 4,25 e 51 Gy, a resposta óptica apresenta desvio-padrão de 6\%, ver FIG 36. Esta incerteza de $6 \%$ pode ser justificada pelas incertezas nas doses obtidas pelas irradiações no reator. 


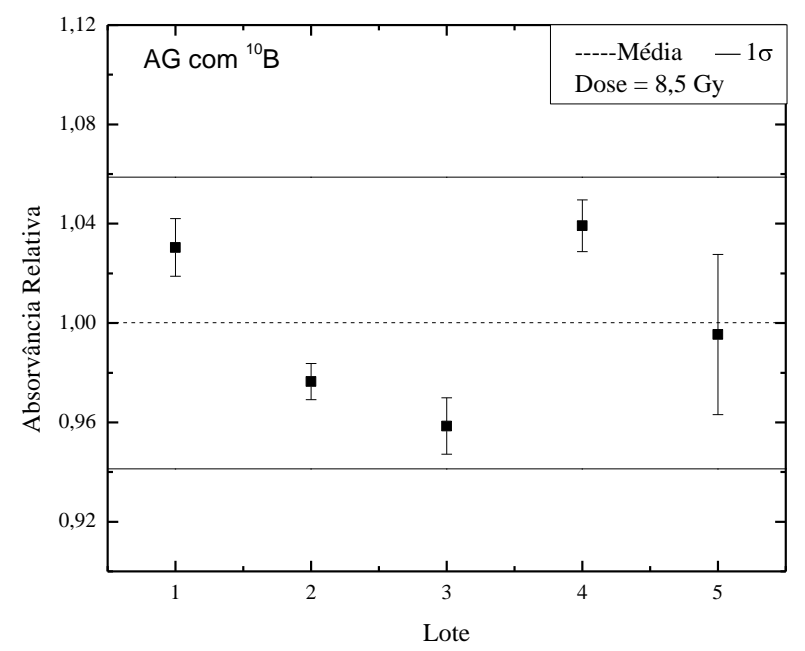

FIGURA 36: Reprodutibilidade inter-lotes para a solução gel de Alanina com ${ }^{10} \mathrm{~B}$ para radiação gama/nêutron.

\subsubsection{Avaliação da dose gama/nêutrons no Reator}

Considerando o número atômico efetivo baixo da solução Fricke gel, 7,42 (Galante, 2006) e a não dependência energética da resposta da solução Fricke gel no intervalo de energias entre $50 \mathrm{keV}$ e $6 \mathrm{MeV}$ (Cavinato, 2008), optou-se por efetuar a curva de dose resposta para radiação gama do ${ }^{60} \mathrm{Co}$.

A FIG.37 apresenta a resposta da solução gel de Alanina com e sem a adição de ${ }^{10} \mathrm{~B}$ para a radiação gama do ${ }^{60} \mathrm{Co}$, no intervalo de dose entre 1 e $20 \mathrm{~Gy}$. Pode ser observado uma sensibilidade $2 \%$ maior na solução com adição de ${ }^{10} \mathrm{~B}$.

A FIG.38, obtida através da subtração entre as curvas da FIG.35 e FIG.37 representa a resposta óptica devido apenas à contribuição dos nêutrons térmicos do reator. 


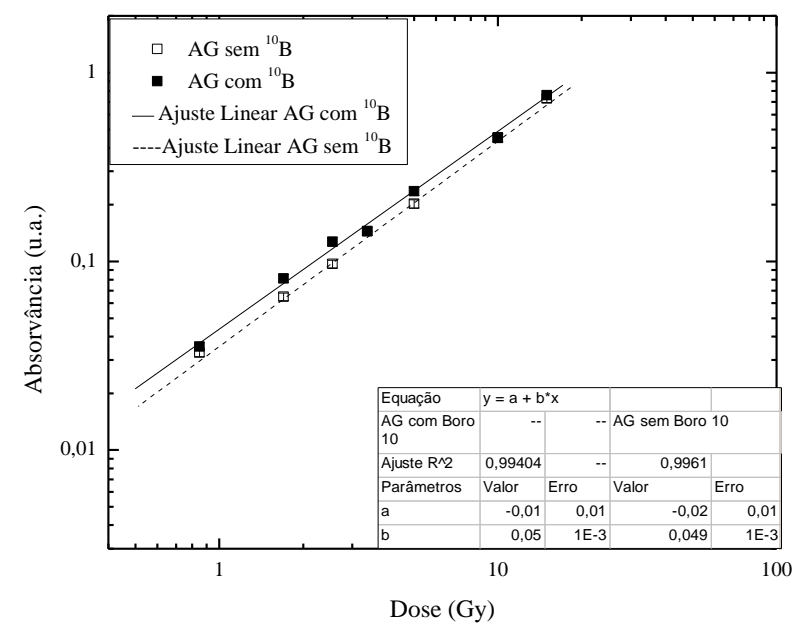

FIGURA 37: Curva de dose-resposta para a solução gel de Alanina com e sem a adição ${ }^{10} \mathrm{~B}$ para radiação gama do ${ }^{60} \mathrm{Co}$.

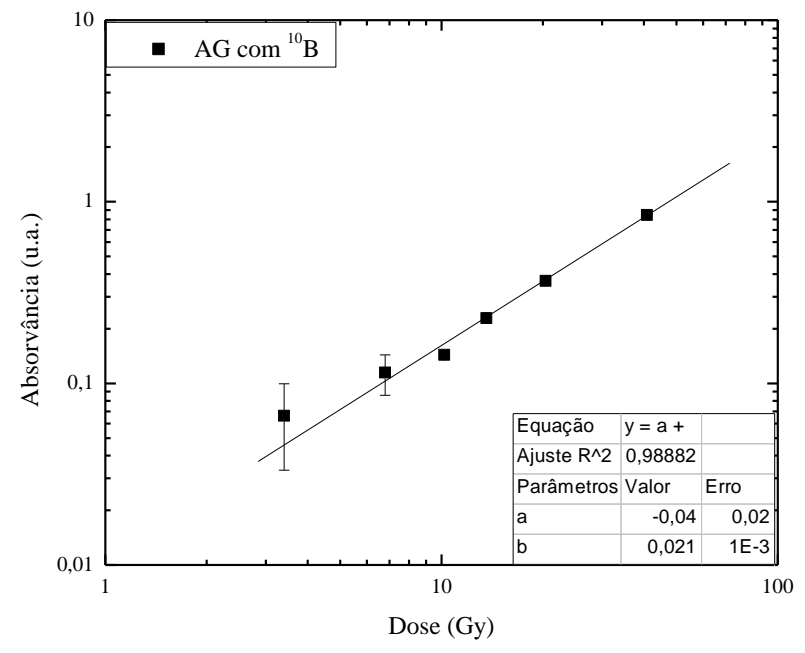

FIGURA 38: Curva de dose resposta para nêutrons térmicos do reator para a solução gel de Alanina com ${ }^{10} \mathrm{~B}$.

Pode ser observado que, no intervalo de doses estudado, a resposta relativa aos nêutrons térmicos também apresenta comportamento linear. 


\subsection{Limite Mínimo de Detecção}

Como pode ser observado na TAB.10, a solução gel de Alanina apresenta limite mínimo de detecção ( $L I D$ ) para elétrons e fótons menores que gama, como esperado, já que as incertezas nas doses são maiores para a radiação gama.

TABELA 10: Limite mínimo de detecção da solução gel de Alanina para diversos tipos de radiação.

\begin{tabular}{ccccc}
\hline Radiação & $D Q(0)$ & $\sigma_{D Q(0)}$ & $f\left(\mathrm{~Gy}^{-1}\right)$ & $L I D(\mathrm{~Gy})$ \\
\hline Gama & 0,69 & 0,03 & 0,062 & 0,05 \\
Fótons $^{*}$ & 0,70 & 0,01 & 0,060 & 0,04 \\
Elétrons & 0,70 & 0,01 & 0,057 & 0,04 \\
\hline${ }^{*}$ Feixe Clínico. & & & &
\end{tabular}

Onde:

$D Q(0)$ : é a resposta óptica média da solução gel de Alanina não irradiada;

$\sigma_{D Q(0)}:$ é o desvio-padrão da resposta óptica média da solução não irradiada;

$f\left(G^{-1}\right)$ : coeficiente angular obtido através da curva de dose resposta da solução gel de Alanina.

\subsection{Incertezas nas medidas}

As incertezas associadas às medidas podem ser classificadas como incertezas do tipo A e incertezas do tipo B. As incertezas do tipo A são determinadas ou estimadas por método estatístico, enquanto que as incertezas do tipo B são determinadas ou estimadas por outros métodos (não-estatístico). Portanto, as incertezas do tipo A são incertezas devido à dispersão do valor dos resultados obtidos em torno do valor verdadeiro, ou seja, de caráter aleatório. Enquanto, as incertezas do tipo B são incertezas devido ao conjunto de medições que apresenta valores igualmente espaçados do valor verdadeiro, originados de erros instrumentais, 
ambientais e observacionais. A incerteza total das medidas é dada pela EQ.9 (Vuolo, 1996).

$$
\sigma_{\text {Total }}^{2}=\sigma_{\text {estatistion }}^{2}+\sigma_{\text {sistemátios }}^{2}
$$

Onde:

$\sigma_{\text {Total }}:$ Incerteza total;

$\sigma_{\text {estatistio }}$ : Incerteza associada ao erro estatístico;

$\sigma_{\text {sistemático }}$ : Incerteza associada ao erro sistemático.

As incertezas do tipo A são:

- Dispersão do valor da medida de Absorvância realizado no espectrofotômetro para cada tipo de radiação. Para radiação do ${ }^{60} \mathrm{Co}$, feixes clínicos de Fótons e Elétrons, e para os nêutrons são 4\%, 4\%, 5\% e 6\%, respectivamente.

As incertezas do tipo B são:

- Medição da massa dos reagentes, que pode ser desprezada, pois a balança utilizada tem uma precisão de $\pm 0,0001$ e a vidraria utilizada é de alta precisão;

- Tempo de estocagem do gel no refrigerador entre 20 e $54 \mathrm{~h}$, acarreta numa imprecisão de $\pm 1,2 \%$, o tempo entre a retirada das amostras do refrigerador e a irradiação destas e o tempo entre irradiação das amostras e leitura destas no espectrofotômetro também geram imprecisões, por isso a retirada do gel sempre era realizada 30 minutos antes da irradiação e a leitura era sempre realizada $1 \mathrm{~h}$ após a irradiação, portanto todas as incertezas podem ser negligenciadas;

- Leitura Espectrofotométrica, também pode ser desprezada, já que a leitura tem uma precisão de $\pm 0,0001$;

- Nas irradiações de ${ }^{60} \mathrm{Co}$ nos irradiadores pertencente ao CTR, a dose absorvida tem uma imprecisão de $\pm 1,7 \%$, portanto pode ser negligenciada, já a imprecisão da posição das amostras nos irradiadores pode ser desconsiderada, já que as amostras podem ser consideradas como objetos pontuais; 
- Nas irradiações com feixes clínicos de fótons e elétrons no acelerador linear pertencente ao Hospital das Clínicas, a dose absorvida tem uma precisão de $\pm 0,001$ Gy, a imprecisão da posição das amostras no acelerador não acarreta uma variação significativa na resposta, pois o erro associado é milimétrico, portanto podem ser negligenciadas;

- Nas irradiações com nêutrons no BH\#3 do reator de pesquisa do IEA-R1 do IPEN, as incertezas associadas aos erros de posicionamento das amostras, tempo de entrada e saída das amostras do BH\#3 não acarretam numa imprecisão significativa, portanto podem ser negligenciadas. Enquanto que a imprecisão na dose é de $\pm 10 \%$, devido à leitura dos dosímetro de LiF Albedo pertencente ao Centro de Engenharia Nuclear/IPEN.

Portanto, a imprecisão da dose para radiação do ${ }^{60} \mathrm{Co}$, feixes clínicos de Fótons e Elétrons, e para nêutrons devido as incertezas do tipo A e B são 4\%, 4\%, $5 \%$ e $12 \%$, respectivamente. 


\section{CONCLUSÕES}

- A solução gel de Alanina é de fácil preparação em laboratório com excelente reprodutibilidade para os diferentes tipos de radiação estudada.

- O Gel Dosimétrico apresenta independência da resposta com taxa de dose e independência energética para todas as radiações que foi realizado o ensaio, levando em consideração o desvio-padrão de $1 \sigma$.

- A resposta óptica apresenta comportamento linear para fótons, elétrons de nível radioterápico e nêutrons térmicos no intervalo de doses estudado.

- A sensibilidade para radiação de ${ }^{60} \mathrm{Co}$, feixes clínicos de fótons e elétrons é a mesma, ou seja, é possível avaliar as doses absorvidas de campos mistos para estes diferentes tipos de radiação.

- Para os feixes de elétrons para aplicações industriais a resposta óptica não apresenta um comportamento linear, e a sua reprodutibilidade é extremamente baixa, devido à destruição de Xilenol pela radiação;

- A dose mínima detectável de 0,05 Gy para radiação gama, 0,04 Gy para fótons clínicos e 0,04 Gy para elétrons clínicos, com uma precisão de 3 desvios padrão, ou seja, 99,99\%.

- Os resultados obtidos através do emprego da técnica de espectrofotometria de absorção, conjuntamente com outros aspectos estudados descritos anteriormente, indicam um emprego favorável deste dosímetro para a técnica de Imagem por Ressonância Magnética (IRM), mostrando o seu grande potencial de maneira clara na determinação da distribuição tridimensional da dose para as radiações estudadas. 


\section{REFERÊNCIAS BIBLIOGRÁFICAS}

ABRAGAN, A. The Principles of Nuclear Magnetism. London: Oxford University Press, 1961.

ALENCASTRO, R. B.; PEIXOTO, J. S.; PINHO, L. R. N. Química Orgânica. Ed. Guanabara Koogan S.A., 1978.

ALLINGER, N. L; CAVA, M. P.; JONGH, D. C; JOHNSON, C. R.; LEBEL, N. A; STEVENS, C. L. Organic Chemistry. New York, N. Y.1976.

ANDERSON, C.M.; EDELMAN, P.A.; TURSKI, P.A. Clinical Magnetic Resonance Angiography. New York: Raven, 1993.

ATTIX, F.H. Introduction to radiological physics and radiation dosimetry. London.: John Willey \& Sons, 1986.

ATTIX, F.H.; ROESCH, W.C. Radiation Dosimetry. New York and London: Academic, 1968.

BALDOCK, C. Historical overview of the development of gel dosimetry: a personal perspective. Journal of Physics, vol. 56, p. 14-22, 2006.

BALDOCK, C.; HARRIS, P. J.; PIERCY, A. R.; HEALY, B. Experimental determination of the diffusion coefficient in two-dimensional in ferrous sulphate gels using the finite element method. Australasian Physical and Engineering Sciences in Medicine, vol.24, ed.1, p.19-30, 2001.

BAFFA, O; FERNANDES, J.P.; PASTORELLO, B.F.; ARAÚJO, D.B. Dosimetria com géis poliméricos através da relaxometria em imagens por ressonância magnética. In: XI CONGRESSO BRASILEIRO DE FÍSICA MÉDICA, Junho 14-17, 2006, Ribeirão Preto.

BARAS, P.; SEIMENES, I.; KIPOUROS, P. ; PAPGIANNIS, P. ; ANGELOPOULOS, A ; SAKELLIOU, L. ; PAPPAS, E. ; BALTAS, D. ; KARAISKOS, P. ; SANDILOS, P. ; VLACHOS, L. Polymer Gel Dosimetry using a Three-Dimensional MRI Acquisition Technique. Medical Physics, vol. 29,ed. 11, p.2506 - 2516, 2002.

BERO, M.A.; GILBOY, W.B.; GLOVER, P.M. Radiochromic gel dosemeter for threedimensional dosimetry. Radiation Physics and Chemistry, v. 61, p. 433-435 (2001). 
BERO, M. A. ; GILBOY, W. B. ; GLOVER, P. M. ; EL-MASRI, H. M. Tissue-equivalent Gel for Non-Invasive Spatial Radiation Dose Measurements. Nuclear Instruments and Methods in Physics Research Section B: Beam Interactions with Materials and Atoms, Vol. 166-167, p 820-825, 2000.

BERO, M. A.; GILBOY, W. B.; GLOVER. P. M.; JENNESON, P. M.; MORTON, E. J. Three-Dimensional Radiation Dose Measurements with Transparent Media and Optical Readout Techniques. In: SRP INTERNATIONAL SYMPOSIUM, Junho 14-18, 1999, Southport.

BLOEMBERGEN, N.; MORGAN, L. O. Journal of Chemistry Physics, vol. 34, p. $842-850,1961$.

BOAS, M.L.; Mathematical Methods in the Physical Sciences. New York: Wiley \& Sons, 1966.

BURICE, P. Y. Organic Chemistry. New Jersey: University of California Santa Barbara Prentice Hall-Upper Saddle River, 1998.

CAMPOS, M. M. Fundamentos de Química Orgânica. São Paulo, S. P. Ed Edgard Blücher Ltda, 1980.

CAVINATO, C.C.; RODRIGUES, L..L. Estudo da estabilidade da resposta espectrofotométrica do dosímetro Fricke Gel. In: XI CONGRESSO BRASILEIRO DE FÍSICA MÉDICA, Junho 14-17, 2006, Ribeirão Preto.

CAVINATO, C.C. Study of the stability, reproducibility and dose rate dependence of the fricke gel dosimeter developed at IPEN. In: INTERNATION NUCLEAR ATLATIC CONFERENCE 2007, Setembro 30 a Outubro 5, 2007, Santos.

CAVINATO, C.C. Padronização do método de dosimetria Fricke gel e avaliação tridimensional de dose empregando a técnica de imageamento por ressonância magnética. 2009. Dissertação (Mestrado) - Instituto de Pesquisas Energéticas e Nucleares - IPEN/CNEN-SP, São Paulo.

COSTA, Z.M. Desenvolvimento de Sistemas de DL-Alanina para dosimetria da Radiação Gama de Elétrons. 1994. Dissertação (Mestrado) - Instituto de Pesquisas Energéticas e Nucleares - IPEN/CNEN-SP, São Paulo.

CHU, W. C. Radiation Dosimetry Using Frick-Infused Gels and Magnetic Resonance Imaging. Proc. Nucl. Sci. v. 25,1, p. $1-11,2001$.

DONG, R. H.; GAO, Z.; HU, Z.; XU, W.; PAN, L. Preliminary Application of Gamma Knife in the Treatment of Nasopharyngeal Carcinoma. Stereotactic and Functional Neurosurgery, vol.66, suplem. 1, p,201-207, 1996. 
DORAN, S. J. The history and principles of chemical dosimetry for 3-D radiation fields: Gels, polymers and plastics. Applied Radiation Isotopes, vol. 67, ed. 3, p. 393-398, 2009.

DURHAM, J. Concepts, quantities, and dose limits in radiation protection dosimetry. Radiation Measumerents, vol. 41, p. S28-S35, 2007.

FONG, P. M.; KEIL, D. C.; DOES, M. D., GORE, J. C. Polymer gels for magnetic resonance imaging of radiation dose distributions at normal room atmosphere. Physics in Medicine and Biology,vol. 46, ed.12, p.3105-3113, 2001.

FRICKE, H.; MORSE, S. The chemical action of roentgen rays on dilute ferrous sulfate solutions as a measure of dose. Am. J. Roent. Rad. Ther., v. 18, p. 430-432, 1927.

GALANTE, A.M.S.; CAMPOS, L.L. Characterization of a Fricke gel solution to be applied in 3D dosimetry of radiotherapy treatment planning systems. 2006. Trabalho apresentado ao $10^{\text {th }}$ International Symposium on Radiation Physics, Coimbra, 2006. Não publicado.

GALANTE, A.M.S.; CAMPOS, L.L. Spectrophotometric analysis of Fricke gel dosimeters irradiated using a gelatin breast phantom. 2006. Trabalho apresentado ao $10^{\text {th }}$ International Symposium on Radiation Physics, Coimbra, 2006. Não publicado.

GALANTE, A.M.S.; CAMPOS, L.L. Chemical dosimeters development at IPEN for the radiation processes quality control. In: CAMILLERI, A.N. (Ed.). Radiation physics research progress. New York, NY: Nova Science, 2008. p. 355-384.

GALANTE, O.L. Padronização do Dosímetro de Alanina. 1999. Dissertação (Mestrado) - Instituto de Pesquisas Energéticas e Nucleares - IPEN/CNEN-SP, São Paulo.

GAMBARINI, G.; BIRATTARI, C.; COLOMBI, C.; PIROLA, L.; ROSI, G. 2. Fricke Gel Dosimetry in Boron Neutron Capture Therapy. Radiation Protection Dosimetry. v. 101, p. 419-22, 2002.

GAMBARINI, G.; BIRATTARI, C.; MONTI, D.; FUMAGALLI, M.L.; VAI, A.; SALVADORI, P.; FACCHIELLli, L.; SICHIROLLO, A.E.. Fricke-Infused Agarose Gel Phantoms for NMR Dosimetry in Boron Neutron Capture Therapy and Proton Therapy. Radiation Protection Dosimetry, v. 70, p. 571-575, 1997.

Gay, C.; Collins, J.; Gebicki, M. Determination of Iron in Solutions with Ferric-Xylenol Orange Complex. Anal. Bioch. v. 273, p. 143 - 148, 1999. 
GORE, J. C.; YANG, Y. S.; SCHULZ, R. I. Measurement of Irradiation Dose distribution by Nuclear Magnetic Resonance (NMR) Imaging. Physical Medical and Biology, v. 29, p. 1189-97, 1984.

GREENSTEIN, J.; WINITZ, M. Chemistry of the Amino Acids. New York, Robert E. Krieger Publishing Company, INC, 1986.

GRÉGOIRE, V.; DE NEVE, W.; EISBRUCH, A.; LEE, N.; DEN WEYNGAERT, D.V.; GESTEL, D.V. Intensity-Modulated radiation Therapy for Head and Neck Carcinoma. The Oncologist, v. 12, p. 555-564, 2007.

GRIFFIN JR, R. W. Química Orgânica Moderna. Barcelona:

Ed Reverte, 1970.

GUPTA, B.L.; BHAT, R.M.; NARAYAN, G.R.; NILEKANI, S.R. Free Radical Dosimetry by Chemical Readout. In: J.DOBO; P. HEDVIG; R.SCHLLER. Radiation Chemistry: proceedings of a symposium on ... held in Bombay, India, 1982.

GUPTA, B.L.; BHAT, R.M.; NARAYAN, G.R.; NILEKANI, S.R. A Spectrophotometric Readout Method for Free Radical Dosimetry. Radiat. Phys. Chem., v. 26(6) : p. 64756, 1985.

GUPTA, B.L.; BHAT, R.M.; NARAYAN, G.R.; NILEKANI, S.R.; GOPAL, N.G.S.; KOVACS, A. Dose Intercomparison Using Spectrophotometric Readout Method for Free Radical Dosimetry. Appl. Radiat. Isot., v. 37(2), p. 127-30, 1986.

HOROWITZ, A.L. MRI Physics for Radiologists: a visual approach. 3 ed. New York, N.Y.: Springer-Verlag, 1994.

HUBELL, J.J. Photon Mass Attenuation and Energy Absorption Coefficients. Appl. Radiat. Isot., v. 33, p. 1269 - 1276, 1982.

ICRP, 2005. 2005 Recommendation of the International Commission on Radiological Protection. ICRP Publication, pp 17, Per Wikman, Philosophy Unit, Royal Institute of Technology, Stockholm, Sweden.

IBBOTT, G. S. Gel Dosimetry. JACR Journal of the American College of Radiology, vol.3, Ed. 2, p. 144-146, 2006.

ILIEV, V.; TOMOVA, D.; BILYARSKA, L.; PETROV, L. Photooxidation of xylenol orange in the presence of palladium-modified $\mathrm{TiO}_{2}$ catalysts. Catalysis Communications, v. 5, ed. 12, p. 759-763, 2004.

IAEA. INTERNATIONAL ATOMIC ENERGY AGENCY. "ABSORVED DOSE DETERMINATION IN EXTERNAL BEAM RADIOTHERAPY”, Tech. Rep. Series. no.: 398, Viena: IAEA, 2000. (IAEA-TECDOC-398). 
IAEA. INTERNATIONAL ATOMIC ENERGY AGENCY. "CALIBRATION OF DOSIMETERS USED IN RADIOTERAPY", Tech. Rep. Series. no.: 374, Viena: IAEA, 1994. (IAEA-TECDOC-374).

INTERNATIONAL COMMISSION ON RADIATION UNITS AND MEASUREMENTS. "QUANTITIES AND UNITS IN RADIATION PROTECTION DOSIMETRY". ICRU, 1993. (ICRU-TECDOC-51).

MARYANSKI, M. J.; SCHULTZ, R. J.; IBBOTT, G. S.; GATENBY, J. C.; XIE, J.; HORTON, D.; GORE, J. C. Magnetic resonance imaging of radiation dose distributions using polymer-gel dosimeter. Physics in Medicine and Biology, vol.39, p.1437-1455, 1994.

MIZUNO, E. Y. Desenvolvimento e Caracterização de um gel de Alanina para Aplicação na Medida da Distribuição da Dose de Radiação Usando a Técnica de Espectrofotometria. 2007. Dissertação (Mestrado) - Instituto de Pesquisas Energéticas e Nucleares - IPEN/CNEN-SP, São Paulo.

MORAES, R. Química Orgânica. Ed Saraiva, 1976.

MORAES, C.V.; NICOLUCCI, P.; PIANOSCHI, T.A.; PELÁ, C.A. SIMULAÇÃO MONTE CARLO APLICADA À DETERMINAÇÃO DAS CURVAS DE DEPENDÊNCIA ENERGÉTICA DE UM DOSÍMETRO INDIVIDUAL TERMO-LUMINESCENTE MULTIFILTRO. In: XI CONGRESSO BRASILEIRO DE FÍSICA MÉDICA, Junho 14-17, 2006, Ribeirão Preto.

NUNES, M. G. Avaliação do Desempenho dos Detectores Termoluminescetes de CaSO4:Dy e LiF:Mg,Ti na Dosimetria de Feixes Clínicos de Elétrons, 2008. Dissertação (Mestrado) - Instituto de Pesquisas Energéticas e Nucleares IPEN/CNEN-SP, São Paulo.

PALM, A.; MATTSON, O.. Influence of Sulphuric Acid Contaminants on Fricke Dosimetry. Phys. Med. Biol. v. 45, p. $111-114,2000$.

PODGORSAK, E. B. Radiation Oncology Physics: A Handbook for Teachers and Students. IAEA: Viena, 2005.

PORTAL, F.; Preparation and properties of principal L products. In: OBERHOFER, M.; SCHARMANN, A. Applied Thermoluminescence Dosimetry. Bristol: Adam Hilger, p. 89-115, 1981.

SCHREINER,L. J. Review of Fricke gel dosimeters. Journal of Physics, v.3, p. 9-21, 2004.

SCHULZ, R. J.; GUZMAN, A. F.; NGUYEN, D. B.; GORE, J. C. Dose-response curves for Fricke-infused agarose gels as obtained by nuclear mabnetic resonance. Physics in Medicine and Biology, vol.35, p. 1611-1622, 1990. 
SILVA, N. A.; NICOLUCCI, P.; BAFFA, O. Spatial Resolution of Magnetic Resonance Imaging Fricke-gel Dosimetry is Improved with a Honeycomb Phanton. Medical Physics, vol. 30, ed. 1, p.17-20, 2003.

SILVA, R. T. A Divulgação Científica e a Internet. 2005. Tese (Monografia de final de curso) - Instituto de Física da Universidade de São Paulo, São Paulo.

SOLOMON, I. Nuclear Magnetic. Physical Review, vol 99, p. 559 - 569, 1955.

SOLOMONS, T. W. G. Química Orgânica, Rio de Janeiro, $1^{\circ}$ edição, 1983, reimpressão 1994.

SPINKS, J.W.T.; WOODS, R. J. An Introduction to Radiation Chemistry, Nes York, N.Y.: John Wiley \& Sons, 1964.

TAUHATA, L.; SALATI, I. P. A.; PRINZIO, R. D.; PRINZIO, A. R. D. Radioproteção e Dosimetria: Fundamentos. Rio de Janeiro: Instituto de Radioproteção e DosimetriaCNEN, 2003.

TEH, B. S.; WOO, S.Y.; BUTLER, B. Intensity Modulated Radiation Therapy (IMRT): A New Promising Technology in Radiation Oncology. The Oncologist, v. 4, p. 433442, 1997.

TENÓRIO, R. Avaliando a Viabilidade do uso do Dosímetro Fricke Modificado na Radioterapia. 2001. Dissertação (Mestrado) Universidade de São Paulo - USP, Ribeirão Preto.

VAN BREE NAM; IDZES, M.H.N.; HUIZENGA, H.; MIJNHEER, B.J. Film dosimetry for radiotherapy treatment planning verification of a $6 \mathrm{MV}$ tangential breast irradiation. Radiation Oncol., v. 31, p. 251-255, 1994.

VAN LAERE, K.; BUYSSE, J; BERKEVENS, P. Alanine Dosimetry Using a Spectrophotometric Ferric-Xilenol Orange Complex Readout. Radiat. Phys. Chem., v. 34 (5), p. 863-868, 1989.

VAN LAERE, K.; BUYSSE, J; BERKEVENS, P. Alanine in High-Dose Dosimetry: Spectrophotometric an Elecrochemical Readout Procedures Compared with ESR. Appl. Radiat. Isot., v. 40 (10-12), p. 885-895, 1989.

VUOLO, J. H. Fundamentos da Teoria dos Erros. 2.ed. São Paulo: Edgar Blücher, 1996. 